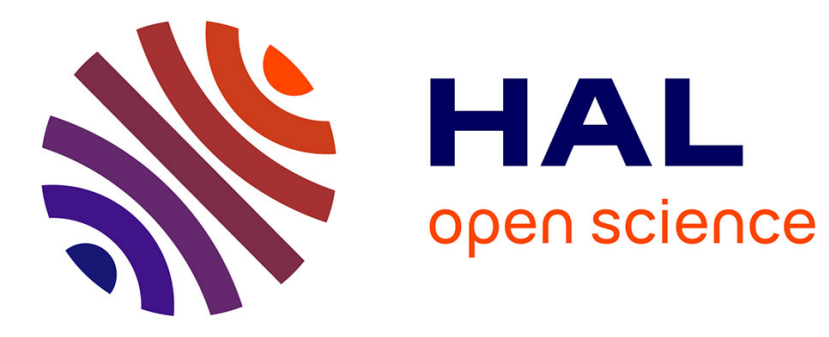

\title{
Investigation of some numerical issues in a chemistry-transport model: Gas-phase simulations
}

Vivien Mallet, Adélaïde Pourchet, Denis Quélo, Bruno Sportisse

\section{To cite this version:}

Vivien Mallet, Adélaïde Pourchet, Denis Quélo, Bruno Sportisse. Investigation of some numerical issues in a chemistry-transport model: Gas-phase simulations. Journal of Geophysical Research, 2007, 112 (D15301), 10.1029/2006JD008373 . inria-00633151

\section{HAL Id: inria-00633151 https://hal.inria.fr/inria-00633151}

Submitted on 6 Jan 2014

HAL is a multi-disciplinary open access archive for the deposit and dissemination of scientific research documents, whether they are published or not. The documents may come from teaching and research institutions in France or abroad, or from public or private research centers.
L'archive ouverte pluridisciplinaire HAL, est destinée au dépôt et à la diffusion de documents scientifiques de niveau recherche, publiés ou non, émanant des établissements d'enseignement et de recherche français ou étrangers, des laboratoires publics ou privés. 


\title{
Investigation of some numerical issues in a chemistry-transport model: Gas-phase simulations
}

\author{
Vivien Mallet, ${ }^{1,2}$ Adélaïde Pourchet, ${ }^{1}$ Denis Quélo, ${ }^{1,2}$ and Bruno Sportisse $e^{1,2}$ \\ Received 21 December 2006; revised 19 March 2007; accepted 4 May 2007; published 2 August 2007.
}

[1] Many numerical strategies have been specifically developed for chemistry-transport models. Since no exact solutions are available for 3-D real problems, there are only few insights to choose between alternative numerical schemes and approximations, or to estimate the performance discrepancy between two approaches. However it is possible to assess the importance of numerical approximations through the comparison of different strategies. We estimated the impact of several numerical schemes for advection, diffusion and stiff chemistry. We also addressed operator splitting with different methods and operator orders. The study is performed with a gas-phase Eulerian model from the modeling platform Polyphemus. It is applied to ozone forecasts mainly over Europe, with focus on a few key species: ozone, nitric oxide, nitrogen dioxide, sulfur dioxide and hydroxy radical. The outcome is a ranking of the most sensitive numerical choices. It stresses the prominent impact of the advection scheme and of the splitting time step.

Citation: Mallet, V., A. Pourchet, D. Quélo, and B. Sportisse (2007), Investigation of some numerical issues in a chemistry-transport model: Gas-phase simulations, J. Geophys. Res., 112, D15301, doi:10.1029/2006JD008373.

\section{Introduction}

[2] Air Pollution Modeling is based on the so-called chemistry-transport models (CTMs in the sequel [Seinfeld and Pandis, 1998; Jacobson, 2005]). These three-dimensional models solve the Reaction-Diffusion-Advection Partial Differential Equations that describe the time and space evolution of reactive trace species in the atmosphere. They are now widely used for many applications: process study (in order to investigate a given physical process), environmental forecast (similar to weather forecast), impact studies (long-term runs in order to evaluate the impact of different scenarios for emissions), inverse modeling of key parameters (on the basis of the coupling between observational data and model outputs), and so on.

[3] These models are characterized by their large dimension. Up to hundreds of species have to be taken into account in current comprehensive gas-phase mechanisms (such as Gery et al. [1989] and Stockwell et al. [1997]). The dimension may be larger for models describing aerosols (particulate matter).

[4] Another key feature of these models is the wide range of spatial scales and timescales. Many processes occur at microphysical scales (of magnitude 1 micrometer; for instance, mass transfer) while the characteristic size of grid cells is of magnitude $10 \mathrm{~km}$ (or even $100 \mathrm{~km}$ ) for regional/

\footnotetext{
${ }^{1}$ Centre d'Enseignement et de Recherche en Environnement Atmosphérique, École Nationale des Ponts et Chaussées-Électricité de France Recherche et Développement, Champs-sur-Marne, France.

${ }^{2}$ CLIME, Institut National de Recherche en Informatique et en Automatique-École Nationale des Ponts et Chaussées, Rocquencourt, France.

Copyright 2007 by the American Geophysical Union. 0148-0227/07/2006JD008373\$09.00
}

continental modeling. The range of timescales, especially for chemical reactions, is also wide: from milliseconds for reactive species (radicals) to days or months for more stable species.

[5] As a result of these features, the numerical simulation associated to such models is recognized to be quite difficult. We refer for instance to the monograph by Zlatev [1995], to Sportisse [2007] or to the primary article by McRae et al. [1982]. The difficulties include many "classical topics" of numerical analysis, including the following: (1) numerical advection schemes are applied to flows with strong gradients (near point sources), and the issue related to numerical diffusion is therefore usually underlined; (2) for many reasons (detailed below), the processes are usually split (operator splitting) and appropriate algorithms have to be used to minimize splitting errors; and (3) (operator splitting) the wide range of chemical timescales implies the stiffness of the resulting ordinary differential equations, and implicit (or at least tailored) algorithms have to be used with a CPU/ accuracy tradeoff to be optimized. These issues have often been addressed in the literature since the early $80 \mathrm{~s}$. We first refer to the review by Verwer et al. [2002] and to many related works [e.g., Verwer et al., 1999; Sandu et al., 1997b, 1997a] for stiff solvers and [Lanser and Verwer, 1999; Sportisse, 2000] for operator splitting.

[6] Most of these works have been performed in simplified cases, that is to say with simplified gas-phase mechanisms, or in $0-\mathrm{D}$ or 1-D applications. A key point for 3-D atmospheric models is however the large amount of uncertainties in the input data and in the physical parameterizations. These complicated models appear to be highly "stable": this is not so easy for a change in numerical schemes to drastically modify the outputs of some target 
species such as ozone (a usual concern in gas-phase models).

[7] The key question for a modeler is to know if there is really, among many available algorithms, a "numerical issue": is there an impact of different numerical strategies in 3-D real cases? Of course, this cannot be answered outside the context of global uncertainties associated to models (including the uncertainties related to data, physical parameterizations and numerics). We refer for instance to Russell and Dennis [2000] and Mallet and Sportisse [2006a] for a deeper investigation of these points.

[8] The objective of this paper is to briefly review the numerical issues listed above and to try to answer this question. We do not propose new algorithms (apart from specific points) but we perform a comprehensive numerical study of these topics with a real 3-D application (air quality modeling mainly over Europe). Even if the tests are made with a specific model, one can expect that the conclusions obtained with our modeling platform can be extended to most of the CTMs.

[9] The focus of this paper is on gas-phase models. The extension to aerosol models is a rather different issue because the numerical simulation of the General Dynamics Equation for aerosol implies other processes with specific numerical behaviors. Moreover, the numerical simulation of aerosols is mainly driven by a coarse discretization (due to the involved computation costs). The extension to aerosol modeling will be the subject of a follower of this paper.

[10] This paper is organized as follows. We briefly describe the chemistry-transport models in section 2. We use the Polyphemus platform [Mallet et al., 2007] to perform the tests. This platform is representative of stateof-the-science numerical tools (used for operational purposes). We also describe the case study: mainly air pollution over Europe for a few days in summer 2001. An evaluation of numerical performance is also described, especially in term of CPU time. We address some issues related to splitting in section 3, to stiffness in section 4 (with a focus on positivity), to advection and diffusion in section 5 .

[11] For the sake of clarity, we have omitted many numerical tests and have only reported the most significant results. In particular, the main results obtained for the regional case (over northern France, in 1998) are briefly summarized in conclusion. The complete study related to this article is given by Pourchet et al. [2005].

\section{Background and Setup}

\subsection{Atmospheric Dispersion}

[12] The time and space evolution of atmospheric trace species is given by the reactive-dispersion equation [e.g., Seinfeld and Pandis, 1998]. For the air concentration $c_{i}$ of species $X_{i}$ (the species are labeled by $i$ ), the evolution is governed by

$$
\frac{\partial c_{i}}{\partial t}+\operatorname{div}\left(V(x, t) c_{i}\right)=\operatorname{div}\left(\rho K \nabla \frac{c_{i}}{\rho}\right)+\chi_{i}(c, T(x, t), t)+S_{i}(x, t) .
$$

$x \in \mathbf{R}^{3}$ and $t$ stand for the space and time coordinates, respectively. Notice that the CTMs are usually based on offline coupling with meteorological models. The equations require meteorological inputs that may be (1) either direct outputs of meteorological models, such as the wind velocity $V$, the temperature $T$ or the air density $\rho$, or (2) parameterized fields such as the eddy diffusivity matrix $K$, estimated from raw meteorological outputs.

[13] $S_{i}(x, t)$ represents the volume emissions of species $i$. The chemical production/loss $\chi_{i}$ for species $i$ is given by a chemical mechanism as a function of kinetic rates and concentrations. The kinetic rates are functions of temperature for thermal reactions and of the actinic flux for photolytic reactions. A key feature is the time dependence of photolysis rates characterized by strong gradients at sunrise and sunset.

[14] Other processes are often added to source terms: scavenging processes (rainout or washout) are usually described by a loss term $-\Lambda_{i}(x, t) c_{i}$, where $\Lambda_{i}$ is a parameterized coefficient.

[15] Boundary conditions (in practice, flux conditions) have to be given at the top of the domain and at ground. At ground, since the vertical wind velocity is zero, they are

$$
-\rho K \nabla \frac{c_{i}}{\rho} \cdot \mathbf{n}=E_{i}(x, t)-v_{i}^{d e p}(x, t) c_{i}
$$

where $\mathbf{n}$ is the upward unitary vector, $E_{i}$ the surface emissions and $v_{i}^{d e p}$ the dry deposition velocity, given as a parameterization based on meteorological data and land use cover.

\subsection{Numerical Platform}

[16] The numerical solution is computed by the Polyphemus platform [Mallet et al., 2007]. Polyphemus is a stateof-the-science modeling platform for air quality, that is used both for research projects and operational applications. It is mainly based on (1) a library for atmospheric parameterizations and preprocessing of meteorological fields, AtmoData [Mallet and Sportisse, 2005b], which computes the physical parameters that appear in the dispersion equation; (2) a set of chemistry-transport models (CTMs in the sequel), including Polair3D [Boutahar et al., 2004] which is used for this work (we assume a CTM is basically a numerical solver for the dispersion equation); and (3) a postprocessing tool, AtmoPy, in order to perform model-todata or model-to-model comparisons, and to compute statistics. Polyphemus is also intended to be used with high-level functionalities, such as sensitivity analysis of model outputs with respect to inputs [Mallet and Sportisse, 2005a], ensemble forecast (multimodels configuration [Mallet and Sportisse, 2006b]) and data assimilation (coupling between model outputs and observational data [Quélo et al., 2005]). A key tool for part of these functionalities is the adjoint model of Polair3D [Mallet and Sportisse, 2004]. The reference configuration of Polair3D used for this work is described thereafter.

[17] The chemical mechanism is RACM [Stockwell et al., 1997], with 72 gas-phase species. The time step is $600 \mathrm{~s}$. The reference splitting method is a source splitting method with boundary conditions taken into account in the diffusion. ROS2 (second-order Rosenbrock method) is the scheme for the time integration of chemical kinetics and diffusion; it is solved with $\gamma=1+\sqrt{2} / 2$ (refer to section 4) and a time step of $600 \mathrm{~s}$. The advection scheme is a third- 
Table 1. Distribution of CPU Time for the Continental and Regional Cases (Reference Configuration)

\begin{tabular}{lcc}
\hline \multicolumn{1}{c}{ Process } & Continental Case & Regional Case \\
\hline Chemistry & $58.6 \%$ & $10.2 \%$ \\
Including kinetic rates & $16.3 \%$ & \\
Including LU decomposition & $16.8 \%$ & \\
Advection & $15.2 \%$ & $83.8 \%$ \\
Including flux limiting & $9.3 \%$ & $52.2 \%$ \\
Diffusion & $22 \%$ & $4.8 \%$ \\
Including vertical diffusion & $8.6 \%$ & $2.1 \%$ \\
\hline
\end{tabular}

order Direct Space Time scheme with a Sweby-type flux limiter (section 5). Besides, the advection is solved without directional splitting. Finally, the diffusion is solved with an horizontal diffusion coefficient $K_{H}$ set to $10000 \mathrm{~m}^{2} \mathrm{~s}^{-1}$ $\left(5 \mathrm{~m}^{2} \mathrm{~s}^{-1}\right.$ at regional scale).

\subsection{Case Studies}

[18] We consider two case studies related to air pollution modeling (photochemistry):

[19] 1. The first is a continental application over Europe $\left(\left[40.25^{\circ} \mathrm{N}, 10.25^{\circ} \mathrm{W}\right] \times\left[56.75^{\circ} \mathrm{N}, 22.25^{\circ} \mathrm{E}\right]\right)$. The domain is divided into 65 grid cells along $\mathrm{x}$ (longitude, grid resolution of $0.5^{\circ}$ ), 33 grid cells along y (latitude, grid resolution of $0.5^{\circ}$ ) and 5 grid cells along $\mathrm{z}$, up to $3000 \mathrm{~m}$. This resolution is rather coarse, which is the case in many real applications with CTMs. The time step is set to $600 \mathrm{~s}$ which is a usual value for many CTMs.

[20] 2. The second is a regional application over Lille (northern France). The domain is divided into 42 grid cells along $\mathrm{x}$ (grid resolution of $0.014^{\circ}$ ), 44 grid cells along y (grid resolution of $0.009^{\circ}$ ) and 9 grid cells along $\mathrm{z}$, up to $2780 \mathrm{~m}$. The time step is set to $600 \mathrm{~s}$.

[21] At continental scale, the lateral boundary conditions come from a global model (Mozart 2 [Horowitz et al., 2003]). At regional scale, the lateral boundary conditions are generated by simulations at continental scale with Polair3D.

[22] Unless notified, simulations are performed over seven days. Initial conditions are extracted from a simulation (with the reference configuration) run over several days before the starting date. Transient phases are then avoided.

[23] The results are detailed only for the continental scale. The most significant numerical tests for the regional case are briefly summarized in conclusion.

\subsection{CPU Performances}

[24] Numerical choices have an impact on the accuracy, the stability and also on the code CPU performances. In the reference simulation at continental scale, Polair3D requires about 5 min of CPU time on a Pentium IV (3 Ghz) with Intel Fortan Compiler.
[25] For the continental study, the distribution of most costs (a few functions are excluded such as initialization functions) is the following one: $58.6 \%$ of the time is spent in chemistry, $15.2 \%$ in advection and $22 \%$ in diffusion (Table 1). Chemistry has the largest contribution for CPU due to the computation of the kinetic rates (power and exponential functions) and due to linear algebra (linear systems are solved with a LU method).

[26] For the regional study, $10.2 \%$ of the time is spent in chemistry, $83.8 \%$ in advection and $4.8 \%$ in diffusion. The advection appears to be the prominent process. This comes from the Courant-Friedrichs-Lewy condition (CFL) $V \Delta t /$ $\Delta x \leq 1$ which implies small sub-time-steps (since the grid cells are smaller than for the continental case) in the advection integration. Enforcing the CFL condition requires to perform up to 30 subcycles. Note that the subcycling never occurs at continental scale where the time step (600 s) is small enough.

[27] A large part of the CPU time is devoted to the computation of the numerical flux (52\%). Regarding the high CPU time spent in advection, one can wonder whether the advection scheme is well suited. Notice that a significant speed-up can be obtained with other advection schemes, such as a scheme without flux limiter and a basic upwind scheme (see section 5 for details and the study of accuracy), as indicated in Table 2 .

\subsection{Procedure for Model-to-Model Comparisons}

[28] In order to evaluate the impact of numerics, we have chosen to perform model-to-model comparisons. We do not include comparisons against observations. As other CTMs, our model is tuned with the observations so that a better numerical scheme may deteriorate the performances. On the contrary, a worse scheme can compensate for errors elsewhere. In addition, many numerical changes only have a slight impact (much lower than CTMs errors and uncertainties).

[29] We assess thereafter, for each process, the spread in the results due to several numerical choices. A sensitivity analysis is performed to identify the numerical choices that have a strong impact on the results, and those with a minor impact on the computed fields. If strong differences are found between two schemes, the most accurate scheme (the scheme of highest order, for instance) is advocated. If only minor changes arise, the numerical approximation with the lowest computational cost is advocated. We only pay attention to ground-level concentrations because this is where concentrations are usually needed. In addition, specific problems arise at ground level due to boundary conditions (emissions, deposition velocities).

[30] Let $A=\left(A_{h, i, j}\right)_{h, i, j}$ and $B=\left(B_{h, i, j}\right)_{h, i, j}$ be the results of simulations $\mathrm{A}$ et $\mathrm{B}$, where $h$ is the temporal index, and $i$ and $j$ label the spatial position. The average over space and time of $A$ is $\bar{A}$.

Table 2. Comparison Between CPU Times Needed for Advection With Different Numerical Schemes ${ }^{\mathrm{a}}$

\begin{tabular}{|c|c|c|c|}
\hline & Upwind Scheme & Third Order Without Flux Limiter & Third Order With Flux Limiter \\
\hline Ratio to the reference CPU time & 0.74 & 0.94 & 1.00 \\
\hline CPU time for advection & $74.8 \%$ & $82.4 \%$ & $83.8 \%$ \\
\hline CPU time for flux computation & $34.6 \%$ & $48.2 \%$ & $52.2 \%$ \\
\hline
\end{tabular}

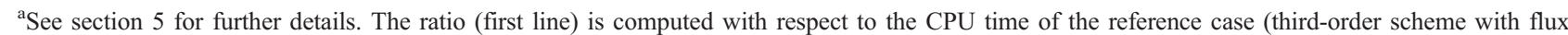
limiter). 
[31] The analysis is mostly based on the time evolution of means and standard deviations of concentrations. Another comparison is done with the analysis of all differences between the two simulations. By assuming that an error below 5\% can be neglected, a number is derived in order to measure the "distance" between two simulations:

$$
\begin{aligned}
& a(A, B)=\frac{\operatorname{card}\left\{(h, i, j) /\left|\Delta_{h, i, j}\right|<5 \%\right\}}{\operatorname{card}\{(h, i, j)\}}, \\
& \text { with } \Delta_{h, i, j}=\frac{A_{h, i, j}-B_{h, i, j}}{\frac{1}{2}(\bar{A}+\bar{B})}
\end{aligned}
$$

where card is the cardinal of a set (number of elements). The amount of relative error below $5 \%, a(A, B)$, is referred as the agreement coefficient. If the agreement coefficient is $100 \%$, the conclusion is that the two simulations are very close. $\Delta$ is referred as the distance between the two simulations. This distance could have been normalized with temporal averages instead of spatiotemporal averages $(\bar{A}$ and $\bar{B})$. We checked that the conclusions remain the same in both cases.

[32] An accurate illustration of the differences is the relative frequency distribution $D$ of $\Delta$. It can also be referred as its density and it satisfies

$\forall \delta \quad \forall \eta>0$

$$
\int_{[\delta, \delta+\eta]} D\left(\delta^{\prime}\right) \mathrm{d} \delta^{\prime}=\frac{\operatorname{card}\left\{(h, i, j) / \Delta_{h, i, j} \in[\delta, \delta+\eta]\right\}}{\operatorname{card}\{(h, i, j)\}}
$$

[33] In practice $\eta$ should be large enough to smooth out $D$. In the sequel, many figures show the relative frequency distribution $D$ (for instance, Figure 2) so that the integral of $D$ over the abscissa range is 0.99 .

[34] The following pollutants are studied: ozone $\left(\mathrm{O}_{3}\right.$; the most studied gas-phase pollutant in photochemistry), nitric oxide (NO; localized near high emission sources), nitrogen dioxide $\left(\mathrm{NO}_{2}\right)$, sulfur dioxide $\left(\mathrm{SO}_{2}\right.$; important for particulate matter and for given emitting sectors) and the hydroxy radical ( $\mathrm{HO}$; a key species for the oxidizing power of atmosphere and a species with a very small timescale).

[35] The same accuracy cannot be reached for all species, because of their spatial distribution (strong gradients, e.g., for $\mathrm{NO}$ ) and their characteristic timescale (much smaller than the numerical time step, e.g., for HO). It is expected that $\mathrm{O}_{3}$ and $\mathrm{SO}_{2}$ are not strongly affected by a numerical change, notably owing to their quite homogeneous spatial distribution. Nitric oxide NO is mainly located near emission sources: it is hard to simulate such a species at continental scale. Hydroxy radical is also hard to compute because of its very high reactivity. Nitrogen dioxide $\mathrm{NO}_{2}$ is intermediate.

[36] To summarize, one can expect that if a numerical change does not affect $\mathrm{HO}$ and $\mathrm{NO}$, this change has no impact. If $\mathrm{NO}_{2}$ concentrations are modified, the numerical change is not negligible. Finally, if concentrations of $\mathrm{O}_{3}$ and $\mathrm{SO}_{2}$ are significantly modified, the system is sensitive to the numerical change.

[37] In the following sections, we first briefly summarize the background and the algorithms and then discuss the results of the numerical tests applied to the continental case study.

\section{Splitting Methods}

\subsection{Background}

[38] Operator splitting methods are then commonly advocated in this context [McRae et al., 1982; Carmichael et al., 1996; Verwer et al., 2002; Sportisse, 2000]. The dispersion equation is then viewed as a sequence of three main processes:

[39] 1. The first process is advection:

$$
\frac{\partial c_{i}}{\partial t}=-\operatorname{div}\left(V(x, t) c_{i}\right)
$$

[40] 2. The second process is turbulent diffusion:

$$
\frac{\partial c_{i}}{\partial t}=\operatorname{div}\left(\rho K \nabla \frac{c_{i}}{\rho}\right) .
$$

[41] 3. The third process includes chemical reactions and source terms:

$$
\frac{\partial c_{i}}{\partial t}=\chi_{i}(c, T(x, t), t)+S_{i}(x, t)
$$

[42] These processes include appropriate boundary conditions, when required. In practice, ground boundary conditions (equation (2)) are integrated with diffusion, and, in advection, zero inflow and outflow fluxes are assumed at ground.

[43] The classical methods and the corresponding numerical analysis are usually given in the linear case:

$$
\frac{d c}{d t}=A c+B c, c(0)=c_{n}
$$

[44] $A$ and $B$ are two linear operators. The concentration $c_{n}$ is current value of the solution at time $t_{n}=n \Delta t$ where $\Delta t$ is the so-called splitting time step. The splitting algorithm computes an estimation $c_{n+1}$ of the solution $c$ at time $t_{n+1}=$ $t_{n}+\Delta t$.

\subsubsection{First-Order Methods}

[45] The simplest splitting method is, of course, as follows:

[46] 1. The first step is to integrate operator $A$ :

$$
\frac{d c^{*}}{d t}=A c^{*} \quad \text { over } \quad[0, \Delta t], c^{*}(0)=c_{n}
$$

[47] 2. The second step is to integrate operator $B$ :

$$
\frac{d c^{* *}}{d t}=B c^{* *} \quad \text { over } \quad[0, \Delta t], c^{* *}(0)=c^{*}(\Delta t) .
$$

[48] We write $c^{*}(\Delta t)=L_{[0, \Delta t]}^{A}\left(c_{n}\right)$ and $c^{* *}(\Delta t)=$ $L_{[0, \Delta t]}^{B}\left(c^{*}(\Delta t)\right)$. The approximation of $c(\Delta t)$ is then $c_{n+1}=$ $L_{[0, \Delta t]}^{B} L_{[0, \Delta t]}^{A}\left(c_{n}\right)$. 
[49] The classical analysis for this method is based on asymptotic expansions with respect to the splitting time step $\Delta t$ supposed to be small. We have then a first-order method unless $A$ and $B$ are commuting operators (in this case the splitting error is 0 since the exponential operators commute). The extension of such an analysis to the nonlinear case may be performed by using the notion of Lie derivative [e.g., Lanser and Verwer, 1999].

\subsubsection{Second-Order Methods}

[50] Strang [1968] has proposed to symmetrize the previous method with the following three steps: (1) The first step is to integrate $A$ over $\left[0, \frac{\Delta t}{2}\right]$ from $c_{n} ;(2)$ the second step is to integrate $B$ over $[0, \Delta t]$; and (3) the third step is to integrate $A$ over $\left[\frac{\Delta t}{2}, \Delta t\right]$. The approximation of $c(\Delta t)$ is then $c_{n+1}=L_{[\Delta t / 2, \Delta t]}^{A} L_{[0, \Delta t]}^{B} L_{[0, \Delta t / 2]}^{A}\left(c_{n}\right)$.

[51] This is a second-order method unless operators commute. We refer to Sportisse [2000] for the analysis of order reduction and the investigation of the optimal sequence in the stiff case (when one operator is chemical kinetics, for instance).

\subsubsection{Internal Splitting}

[52] A different approach is to perform the splitting process at the level of linear algebra. This is sometimes referred as internal splitting [see, e.g., Verwer et al., 1996a].

[53] Let us use an implicit method (for instance Backward Euler) in order to compute the solution of equation (8): $(I-(A+B) \Delta t) c_{n+1}=c_{n}$.

[54] The key idea of internal splitting is then to propose an approximate factorization of the matrix to be inverted. For instance, if we choose $I-(A+B) \Delta t \simeq(I-A \Delta t)(I-B \Delta t)$, this leads to the sequential integration of $(I-A \Delta t) c^{*}=c_{n}$ and $(I-B \Delta t) c^{* *}=c^{*}$. A similar method has been proposed in another context for Navier-Stokes equations [Perot, 1993] where splitting methods are interpreted as approached LU factorizations of matrices.

\subsubsection{Source Splitting Methods}

[55] In order to avoid the transient phases introduced by operator splitting methods (due to the change of initial conditions for each step [see Sportisse, 2000]) alternative methods have been proposed by Sun [1996] (no time splitting) and by Knoth and Wolke [1994] (source splitting).

[56] The key idea is to avoid this change of initial conditions by adding artificial terms. Let us assume that $B$ is a stiff operator (chemical kinetics). In order to avoid a transient phase during the integration of $B$, a slight modification of the first-order method is recommended (with the sequence $A-B)$ :

[57] 1. The first step is to integrate operator $A, c^{*}(\Delta t)=$ $L_{[0, \Delta t]}^{A}\left(c_{n}\right)$.

[58] 2. The second step is to integrate operator $B$ with a complementary source term

$$
\frac{d c^{* *}}{d t}=B c^{* *}+\frac{c^{*}(\Delta t)-c_{n}}{\Delta t} \text { on }[0, \Delta t], \text { with } c^{* *}(0)=c_{n} \text {. }
$$

[59] Notice that the initial condition for the second step has not been modified. A classical analysis of this method proves that this a first-order method. The key point is that transient phases have been eliminated [Sportisse, 2000]. A stability analysis of this algorithm coupled with Rosenbrock methods is given by Verwer et al. [1999]. Even if there is a lack of $A(\alpha)$ stability, this algorithm appears to be stable in practice. It also has many common points with implicitexplicit methods [Ahmad and Berzins, 1997; Ascher et al., 1995; Berzins and Ware, 1996; Frank et al., 1997; Verwer et al., 1996a; Knoth and Wolke, 1998; Wolke and Knoth, 2000; Knoth and Wolke, 1999].

\subsubsection{Splitting of Boundary Conditions}

[60] The key point is to choose the process in which the boundary conditions are taken into account. As a reference, Polair3D solves the ground boundary conditions (equation (2)) with diffusion. The model relies on a finite-volume framework for spatial discretization (which is usually the case for CTMs): the model computes cell-averaged values. In this framework, the boundary conditions may be included as sources for chemistry.

\subsection{Numerical Tests}

\subsubsection{Sequence of Processes Within the Splitting}

[61] In the reference simulation, the splitting sequence is: advection, diffusion and then chemistry (ADC). This sequence is chosen so as to put the stiffest operator at the end, as advocated by Sportisse [2000]. Ground boundary conditions (emissions and deposition velocities) are integrated with diffusion.

[62] The tests show that the key point is the position (in the sequence) of chemistry with respect to diffusion. Simulations in which chemistry is integrated after diffusion (ADC, DCA and DAC) compute (almost) the same concentrations. In the same way, simulations in which diffusion is integrated after chemistry (ACD, CDA and CAD) deliver very similar results. These results are illustrated in Figure 1.

[63] A finer analysis shows slight differences between the simulations in which chemistry and diffusion are kept in the same order (see Figure 2). Nevertheless, when chemistry and diffusion are switched, the agreement between the simulations clearly decreases (see Figure 3 ). The key point therefore lies in the relative position (in the sequence) of chemistry and diffusion, as shown by Sportisse [2000].

\subsubsection{Boundary Conditions}

[64] Ground boundary conditions are included in diffusion. The sensitivity to the chemistry/diffusion sequence may come from these boundary conditions. Figure 4 shows that this is not the main reason. With ground boundary conditions moved to chemistry, the differences are not as high as previously, except for ozone. Meanwhile ozone concentrations are not strongly modified. As a conclusion, the impact of this choice about the ground boundary conditions is not negligible but it does not explain the impact of the splitting sequence.

\subsubsection{Splitting Method}

[65] The use of the method described in section 3.1.2 has a slight impact on concentrations, as shown in Figure 5.

[66] The impact of a change from first-order splitting to internal splitting (section 3.1.3) is still low for ozone and sulfur dioxide. Other species show differences, but lower than in the previous tests. Results are summarized in Figure 6.

[67] As for the impact of source splitting (section 3.1.4), concentrations are slightly modified (Figure 7). Nevertheless, this method improves the stability of the integration. 

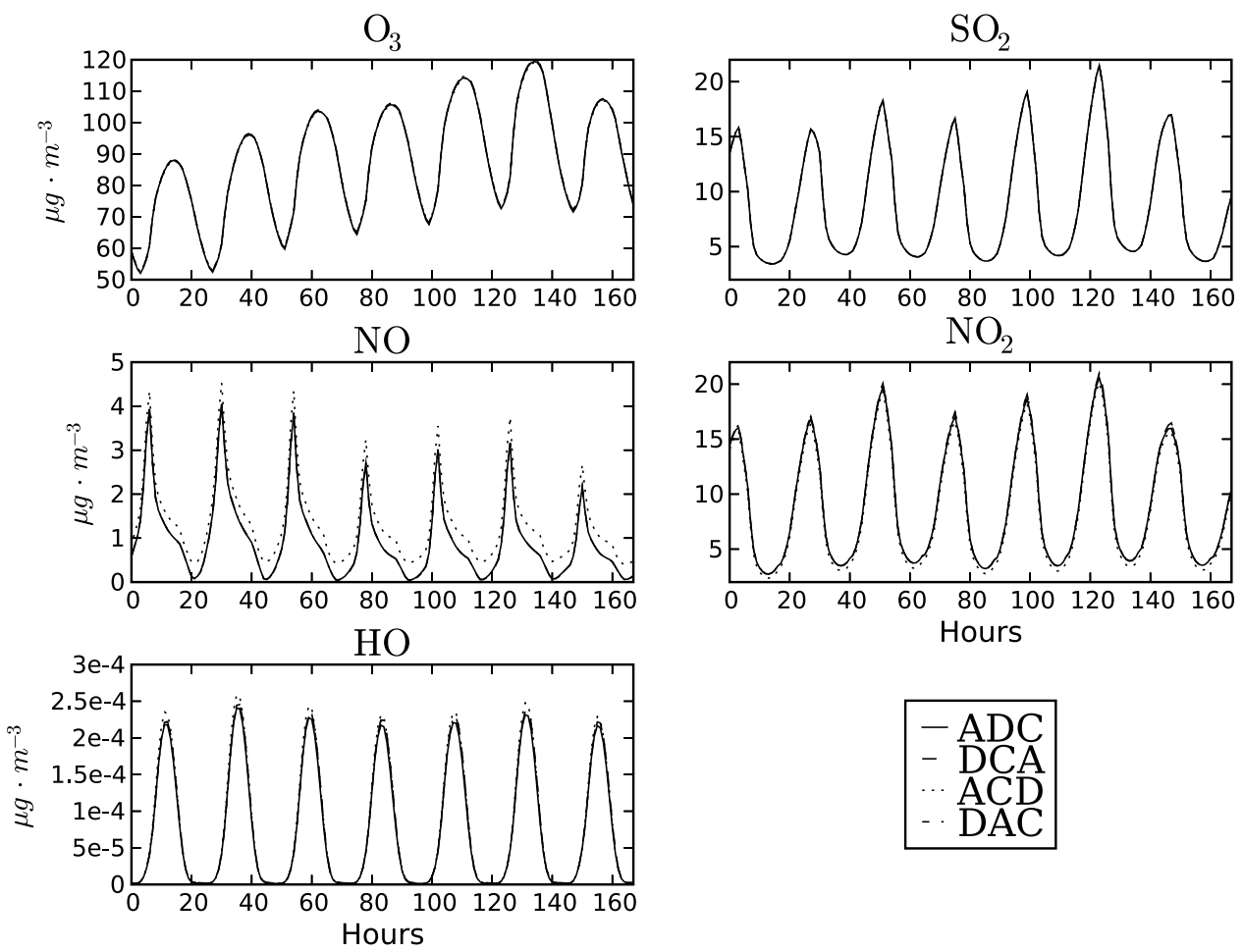

Figure 1. Time evolution of mean concentrations for several splitting sequences. Simulations in which chemistry is before diffusion compute the same concentrations. On the contrary, the simulation ACD shows differences.

Without source splitting, instabilities occur with large time steps such as $1800 \mathrm{~s}$.

\subsubsection{Splitting Time Step}
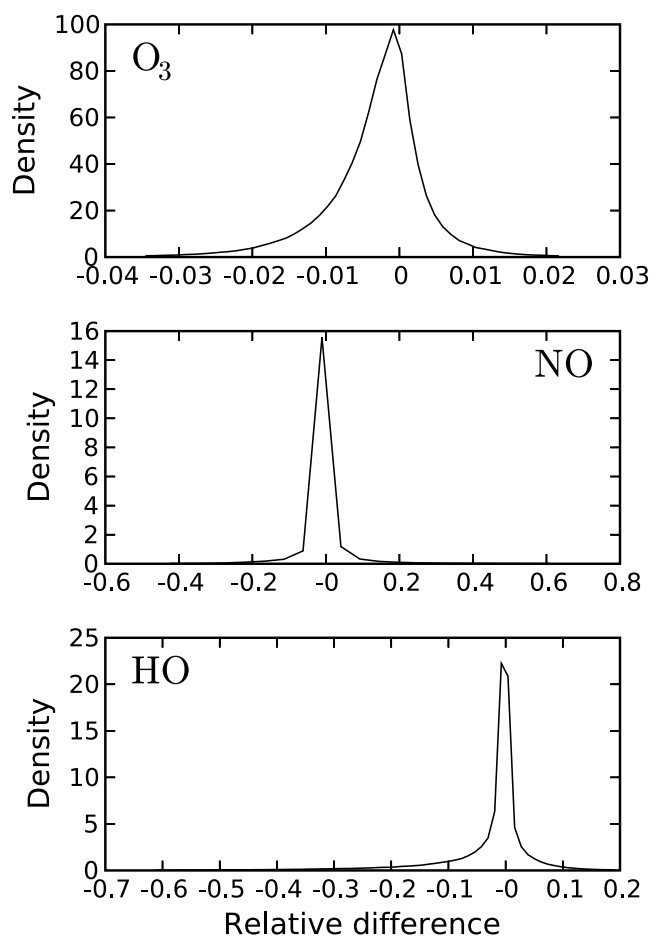

[68] The choice of the splitting time step (also referred as time step) is crucial because the overall computational time is roughly proportional to it. CTMs use time steps higher than the time scales of many chemical reactions. Moreover,
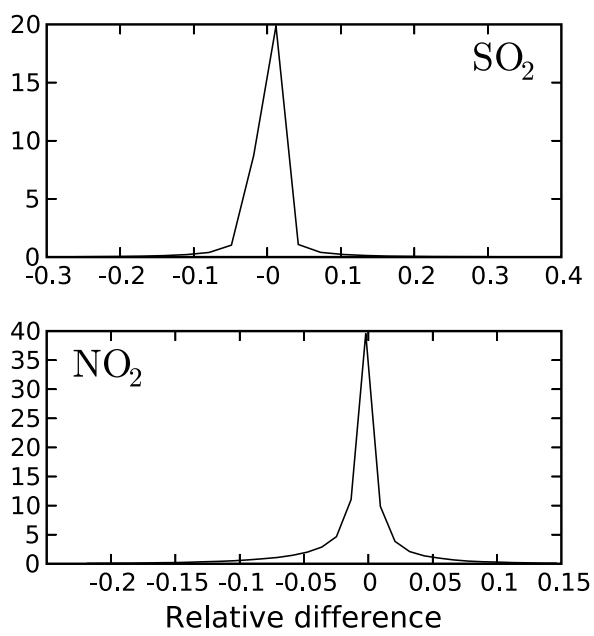

$\mathrm{O}_{3} \quad 99.9 \%$

$\mathrm{SO}_{2} \quad 93.1 \%$

NO $86.4 \%$

$\mathrm{NO}_{2} \quad 88.0 \%$

HO $74.8 \%$

Figure 2. Splitting ADC versus DCA: relative frequency distribution of the distance $\Delta$ and agreement coefficients for the five species. Nonnegligible differences are observed, but the impact remains small. 

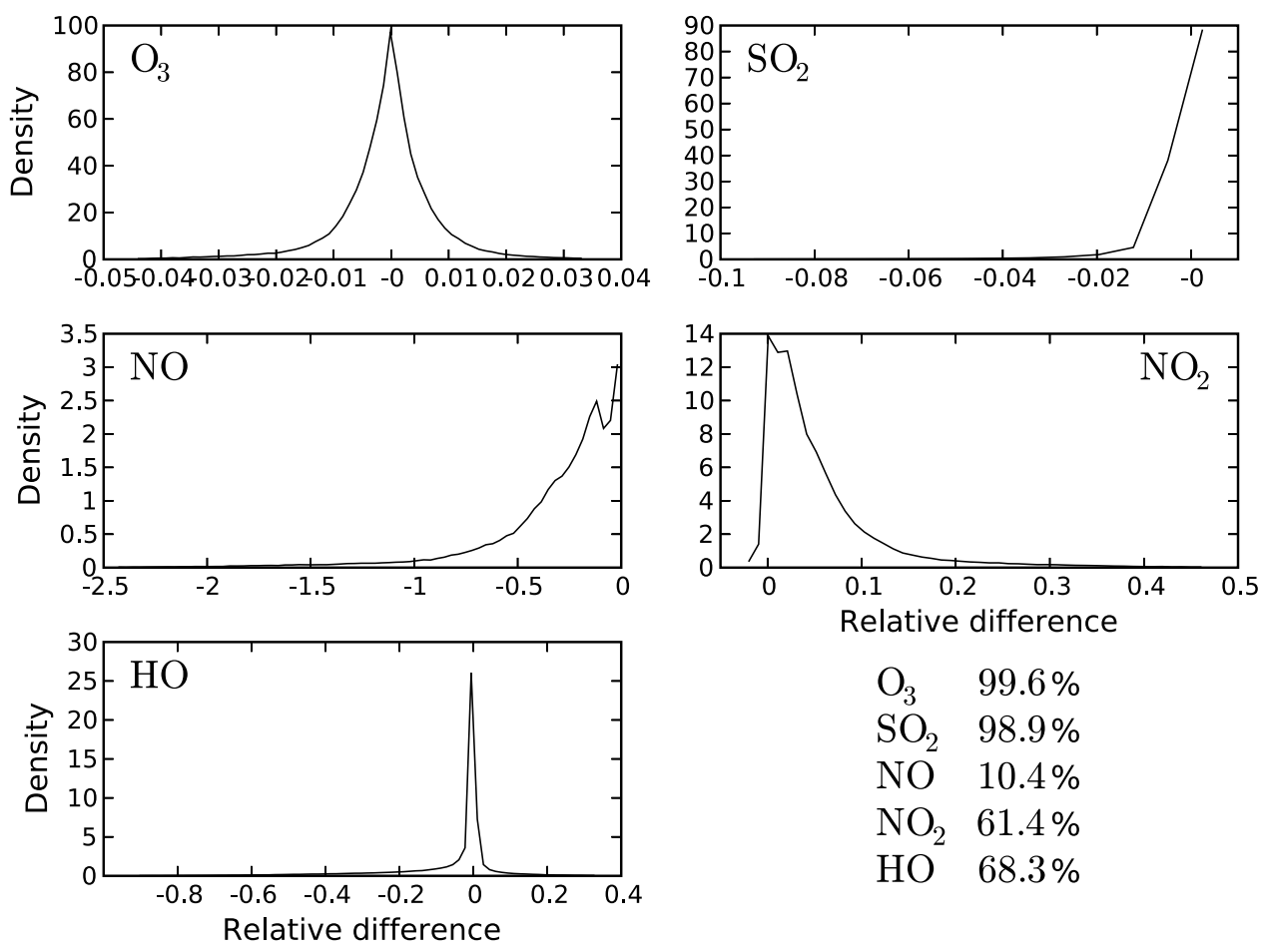

$\begin{array}{ll}\mathrm{O}_{3} & 99.6 \% \\ \mathrm{SO}_{2} & 98.9 \% \\ \mathrm{NO} & 10.4 \% \\ \mathrm{NO}_{2} & 61.4 \% \\ \mathrm{HO} & 68.3 \%\end{array}$

Figure 3. Splitting ADC versus ACD: relative frequency distribution of the distance $\Delta$ and agreement coefficients for the five species. Ozone and sulfur dioxide are slightly modified, while the other species are sensitive to the numerical choice.
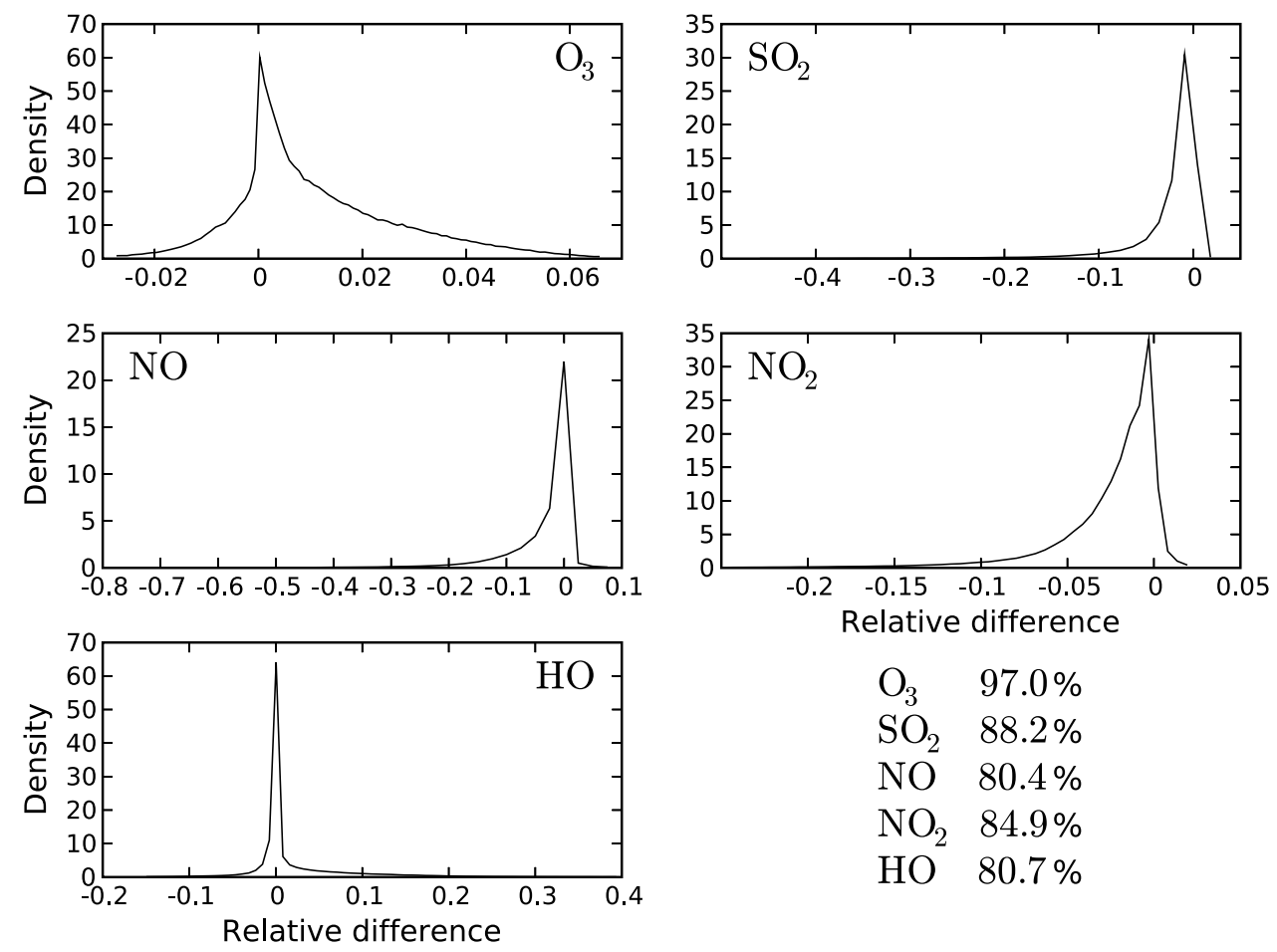

$\mathrm{O}_{3} \quad 97.0 \%$

$\mathrm{SO}_{2} \quad 88.2 \%$

NO $80.4 \%$

$\mathrm{NO}_{2} \quad 84.9 \%$

HO $80.7 \%$

Figure 4. Simulations with ground boundary conditions included in diffusion versus in chemistry: relative frequency distribution of the distance $\Delta$ (see equation (3)) and agreement coefficients for the five species. Ozone is not strongly modified while other species are affected. 

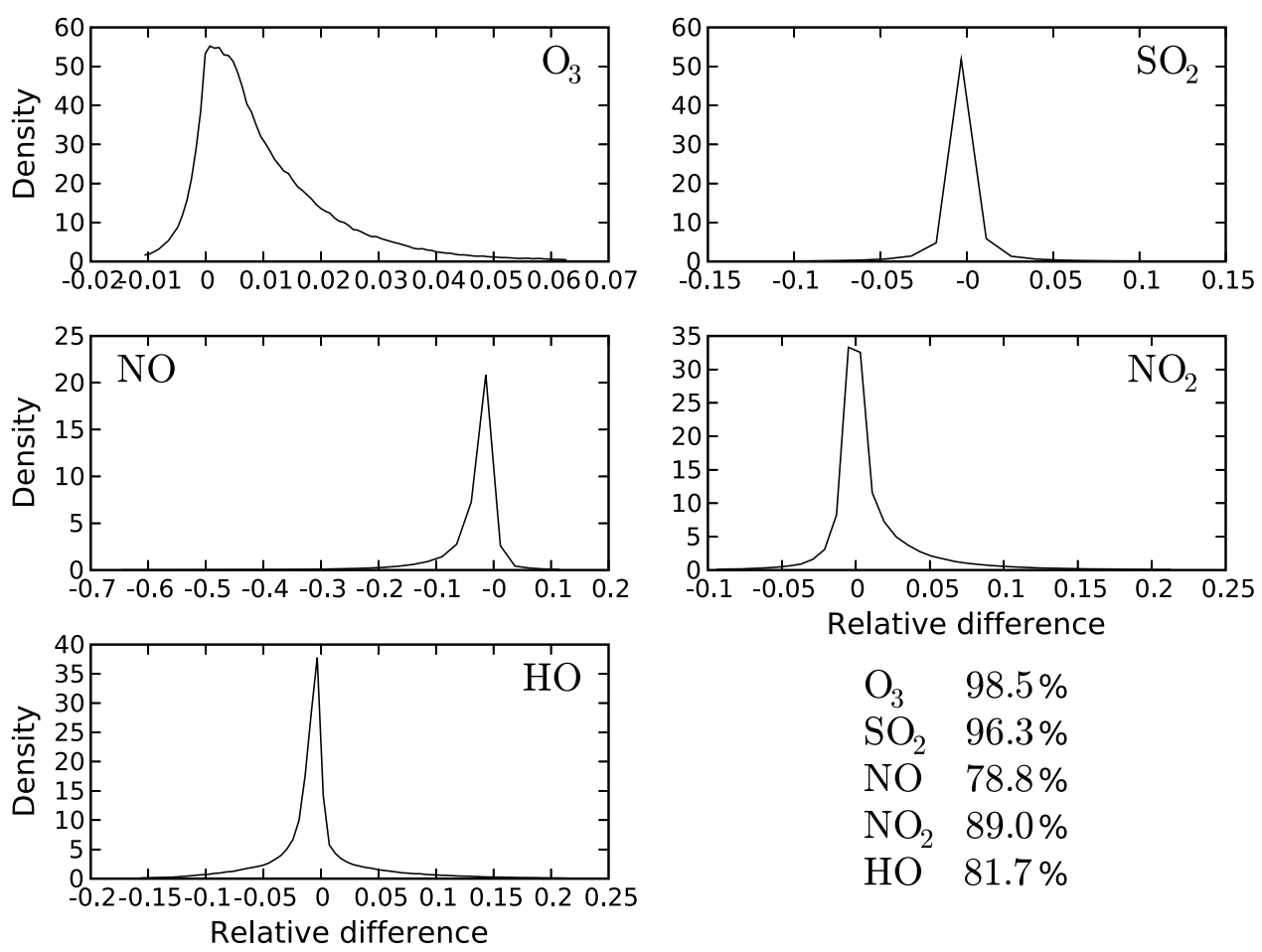

$\mathrm{O}_{3} \quad 98.5 \%$

$\mathrm{SO}_{2} \quad 96.3 \%$

NO $78.8 \%$

$\mathrm{NO}_{2} \quad 89.0 \%$

HO $81.7 \%$

Figure 5. First-order splitting versus second-order splitting: relative frequency distribution of the distance $\Delta$ and agreement coefficients for the five species. Ozone and sulfur dioxide are barely modified; other species are sensitive to the numerical approximation.

there are advection schemes without a CFL restriction [Hundsdorfer and Spee, 1995; Frolkovič, 2002; Lin and Rood, 1996; Restelli et al., 2006]. Time steps may therefore vary in a wide range, maybe up to 1 hour (which is still reasonable for the underlying dynamics).
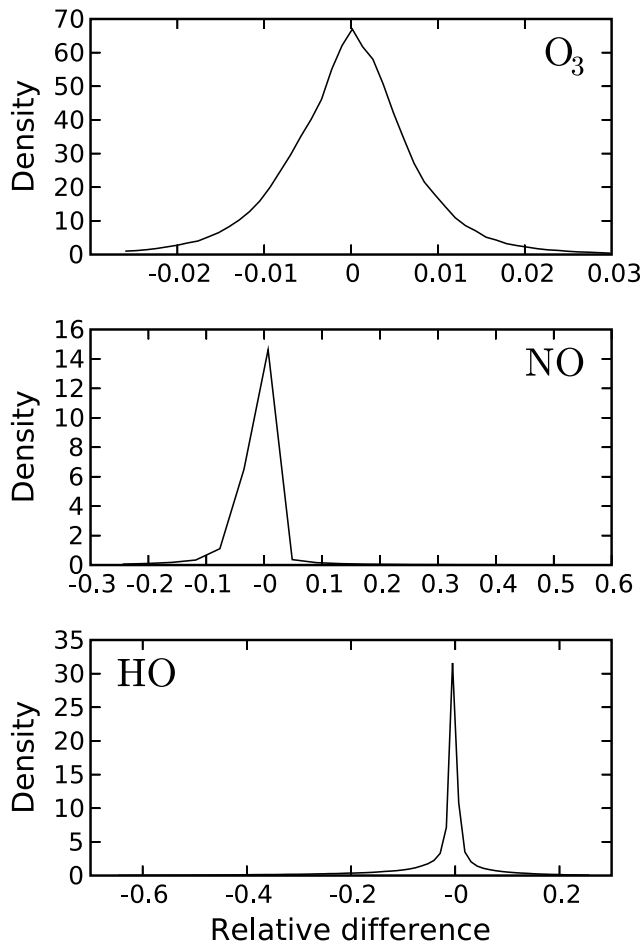

[69] We have used time steps of $30 \mathrm{~s}, 60 \mathrm{~s}, 100 \mathrm{~s}, 200 \mathrm{~s}$, $300 \mathrm{~s}, 600 \mathrm{~s}, 900 \mathrm{~s}, 1200 \mathrm{~s}$ and $1800 \mathrm{~s}$. All results are similar up to $600 \mathrm{~s}$. With time steps above $600 \mathrm{~s}$, the results show noteworthy differences (see Figure 8).

\subsubsection{Conclusion}
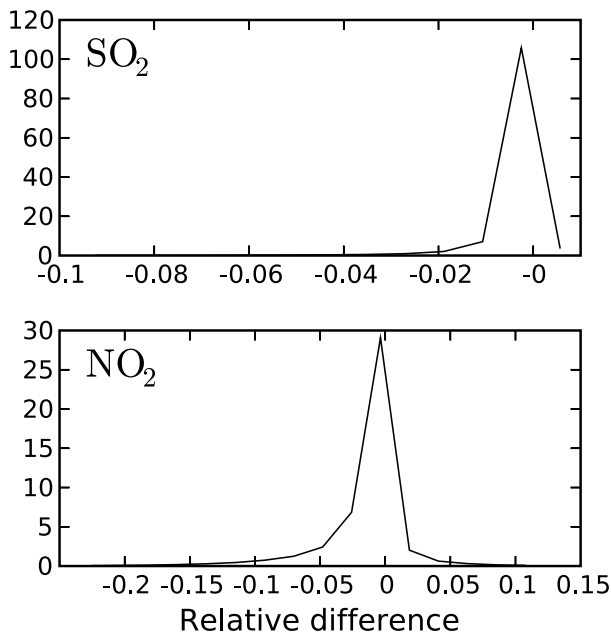

$\mathrm{O}_{3} \quad 99.9 \%$

$\mathrm{SO}_{2} \quad 98.8 \%$

NO $89.5 \%$

$\mathrm{NO}_{2} \quad 91.0 \%$

$\mathrm{HO} \quad 73.5 \%$

Figure 6. First-order splitting versus internal splitting: relative frequency distribution of the distance $\Delta$ and agreement coefficients for the five species. There is a low impact. 

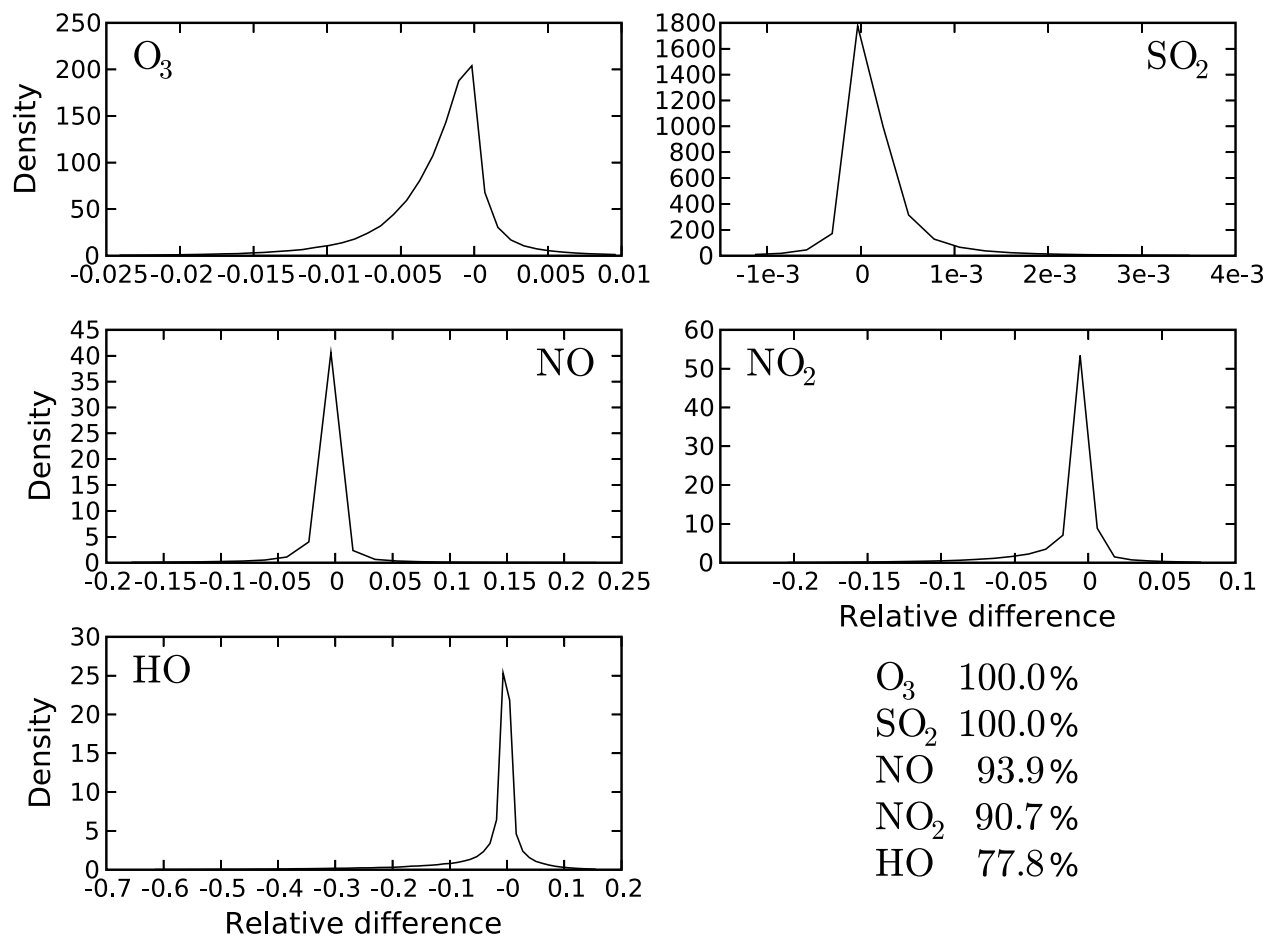

$\mathrm{O}_{3} \quad 100.0 \%$

$\mathrm{SO}_{2} \quad 100.0 \%$

NO $93.9 \%$

$\mathrm{NO}_{2} \quad 90.7 \%$

$\mathrm{HO} \quad 77.8 \%$

Figure 7. First-order splitting versus source splitting: relative frequency distribution of the distance $\Delta$ and agreement coefficients for the five species. There is a very low impact.

[70] The splitting time step (up to $600 \mathrm{~s}$ ) and the scheme order do not make much of a difference. Using a first-order method with a splitting time step of $600 \mathrm{~s}$ is then a good compromise between CPU requirements and accuracy.
Source splitting should be used to improve the stability (without additional CPU costs).

[71] The sequence of processes reveals an impact of the position of chemistry and diffusion in the sequence; chemistry should end the sequence.
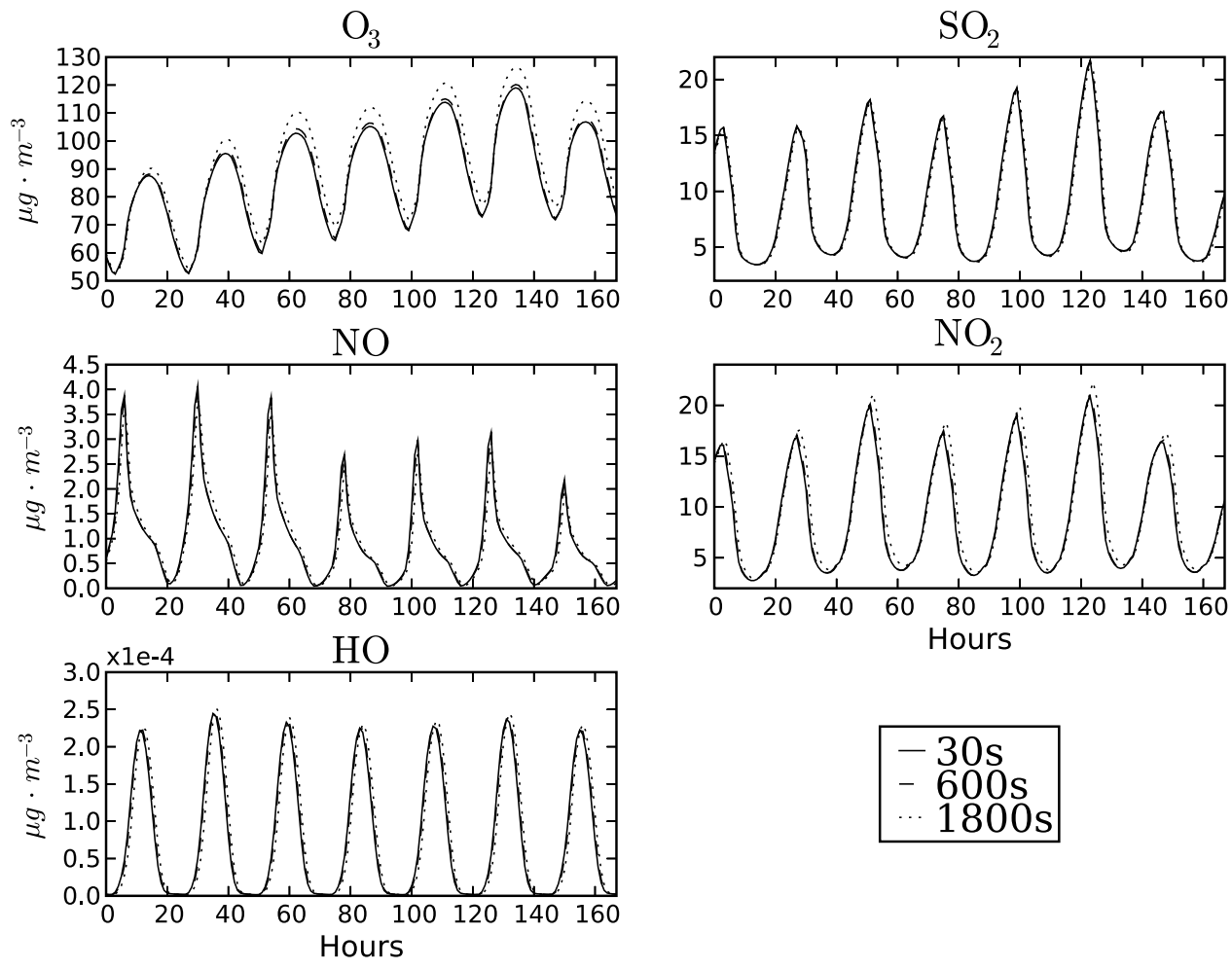

Figure 8. Time evolution of the spatial mean of concentrations computed with three time steps $(30 \mathrm{~s}$, $600 \mathrm{~s}$ and $1800 \mathrm{~s}$ ). The simulation with $1800 \mathrm{~s}$ shows significant differences. 
Table 3. Ratios Between Mean Clipped Concentrations (Absolute Value) and Mean Concentrations ${ }^{\mathrm{a}}$

\begin{tabular}{lclclc}
\hline Species & Ratio, $\%$ & Species & Ratio, $\%$ & Species & Ratio, $\%$ \\
\hline $\mathrm{NO}_{3}$ & 1.01 & $\mathrm{~N}_{2} \mathrm{O}_{5}$ & 0.53 & ETHP & 0.52 \\
OLND & 0.52 & OLNN & 0.48 & APIP & 0.26 \\
KETP & 0.22 & ETEP & 0.06 & $\mathrm{HNO}_{4}$ & 0.03 \\
$\mathrm{HC} 3 P$ & 0.02 & $\mathrm{XO}_{2}$ & 0.02 & XYLP & 0.02 \\
$\mathrm{HC} 5 \mathrm{P}$ & 0.02 & $\mathrm{HC} 8 \mathrm{P}$ & 0.02 & TOLP & 0.02 \\
OLTP & 0.01 & OLIP & 0.01 & ISOP & 0.01 \\
\hline
\end{tabular}

${ }^{\mathrm{a}}$ Only species with a ratio above $0.005 \%$ are included.

[72] The impact of boundary conditions integrated with chemistry (instead of diffusion) remains limited.

\section{Integration of Chemical Kinetics}

\subsection{Background}

[73] The time integration of chemical kinetics is usually a key step for gas-phase CTMs. The reasons are twofold:

[74] 1. Many species are included in comprehensive chemical mechanisms (72 species in the case of the RACM mechanism used in Polyphemus [Stockwell et al., 1997]). This leads to high-dimensional models with the related difficulties.

[75] 2. The wide range of chemical timescales implies the numerical stiffness of the ODEs [Verwer et al., 1996b; Verwer, 1994; Verwer and Simpson, 1995; Sandu et al., 1996, 1997b].

[76] The classical issues of stiff ODEs therefore have to be dealt with: (1) implicit methods instead of explicit ones in order not to be constrained by stringent stability conditions and (2) positivity of concentrations, especially to keep the stability property for chemical kinetics. If the positivity is not satisfied, clipping is applied: the negative concentrations are set to zero. This is widely used (even if this leads to mass addition). An alternative approach is the use of tailored solvers (such as Preussner and Brand [1981]). We also refer to Sandu [2001] for an appropriate algorithm.

[77] Among many candidates, the Rosenbrock methods (Verwer et al. [1999] for gas-phase mechanisms and Djouad et al. [2002] for multiphase models) have appeared to have good skills. For the evolution equation,

$$
\frac{\mathrm{d} c}{\mathrm{~d} t}=f(c, t), c(0)=c_{0}
$$

the second-order Rosenbrock method (ROS2) reads

$$
c_{n+1}=c_{n}+\left(3 k_{1}+k_{2}\right) \frac{\Delta t}{2}
$$

where

$$
\begin{aligned}
& (1-\gamma \Delta t J) k_{1}=f\left(t_{n}, c_{n}\right) \\
& (1-\gamma \Delta t J) k_{2}=f\left(t_{n+1}, c_{n}+\Delta t k_{1}\right)-2 k_{1}
\end{aligned}
$$

$\mathrm{J}$ is an approximation of the Jacobian matrix $\partial f / \partial c$. The parameter $\gamma$ is equal to $1+\sqrt{2} / 2$ to ensure stability (Lstability, see below).

[78] In this section, we focus on the positivity of the concentration. A key point is related to sunset and sunrise. Usually, the linear(ized) system with $f(c)=-\lambda c(\lambda>0)$ is studied. In order to reproduce sunset or sunrise, we introduce a parameter $\beta$ such that $f\left(c, t_{n}\right)=-\lambda c$ and $f\left(c, t_{n+1}\right)=$ $-\beta \lambda c: \beta>1$ for sunrise and $\beta<1$ for sunset.

[79] One easily gets the stability function in this case:

$$
R(\lambda)=\frac{\left(2 \gamma^{2}-(3+\beta) \gamma+\beta\right) \lambda^{2}+(4 \gamma-1-\beta) \lambda+2}{2(1+\gamma \lambda)^{2}}
$$

[80] One way to get the L-stability (i.e., $\lim \lambda_{\rightarrow+\infty} R(\lambda)=0$ ) is to take $\gamma(\beta)$ as the root of the second-order algebraic equation $2 \gamma^{2}-(3+\beta) \gamma+\beta=0$. Since $(3+\beta)^{2}-8 \beta>0$, there are two roots: $\gamma^{ \pm}(\beta)=\left(3+\beta \pm \sqrt{\beta^{2}-2 \beta+9}\right) / 4$.

[81] Note that, in the autonomous case (i.e., $\beta=1$ ), $\gamma^{+}=$ $1+\sqrt{2} / 2$, which is the reference value. With $\gamma^{+}(\beta)$, the stability function becomes

$$
R(\lambda)=\frac{\left(2+\sqrt{\beta^{2}-2 \beta+9}\right) \lambda+2}{2\left(1+\gamma^{+} \lambda\right)^{2}} .
$$

[82] Since $\lambda$ is positive, we have $R(\lambda) \geq 0$, and the scheme is therefore positive. In practice, $\gamma^{+}(\beta)$ is computed by calculating the Jacobian matrix at time $t_{n+1}$ with the same concentrations but with updated photolysis rates. The estimation of $\gamma^{+}(\beta)$ is then given by the highest ratio of the diagonal values between $t_{n}$ and $t_{n+1}$.

\subsection{Numerical Tests}

\subsubsection{Influence of $\Delta t$}

[83] The chemistry may have its own time step (subcycling within the splitting sequence). We have tried different time steps for the chemistry, i.e., $30 \mathrm{~s}, 60 \mathrm{~s}, 100 \mathrm{~s}, 200 \mathrm{~s}$, $300 \mathrm{~s}$ and $600 \mathrm{~s}$. No impact is found.

\subsubsection{Clipping}

[84] First a diagnosis of clipped values is necessary to check whether this may be an issue. The mass added to the system is shown in Table 3 with the ratio of clipped concentrations and mean concentrations. A few species (among the 72 species of the chemical mechanism) are associated with significant ratios. We refer to Stockwell et al. [1997] for the nomenclature of species. Nevertheless, strong corrections may appear at sunrise and sunset, when the system is highly nonautonomous (because of photolysis rates). Table 4 shows the maximum ratio between clipped concentrations and mean concentrations. There are very high ratios.

Table 4. Ratios Between Maximum Clipped Concentrations (Absolute Value) and Mean Concentrations ${ }^{\mathrm{a}}$

\begin{tabular}{lccccc}
\hline Species & Ratio & Species & Ratio & Species & Ratio \\
\hline ETHP & 121.39 & APIP & 95.49 & KETP & 60.00 \\
$\mathrm{NO}_{3}$ & 15.58 & OLND & 13.53 & ETEP & 11.76 \\
$\mathrm{~N}_{2} \mathrm{O}_{5}$ & 7.00 & $\mathrm{HC} 3 \mathrm{P}$ & 6.04 & $\mathrm{XO}_{2}$ & 4.54 \\
$\mathrm{OLNN}$ & 4.42 & XYLP & 4.09 & TOLP & 3.48 \\
$\mathrm{HC5P}$ & 3.36 & $\mathrm{HC} 8 \mathrm{P}$ & 3.29 & OLTP & 2.12 \\
OLIP & 2.06 & $\mathrm{HNO}$ & 1.39 & CSLP & 1.29 \\
ISOP & 0.70 & PHO & 0.70 & $\mathrm{MO}_{2}$ & 0.22 \\
\hline
\end{tabular}

${ }^{\mathrm{a}}$ Only species with a ratio above 0.1 are included. Ratios are not in percent. 

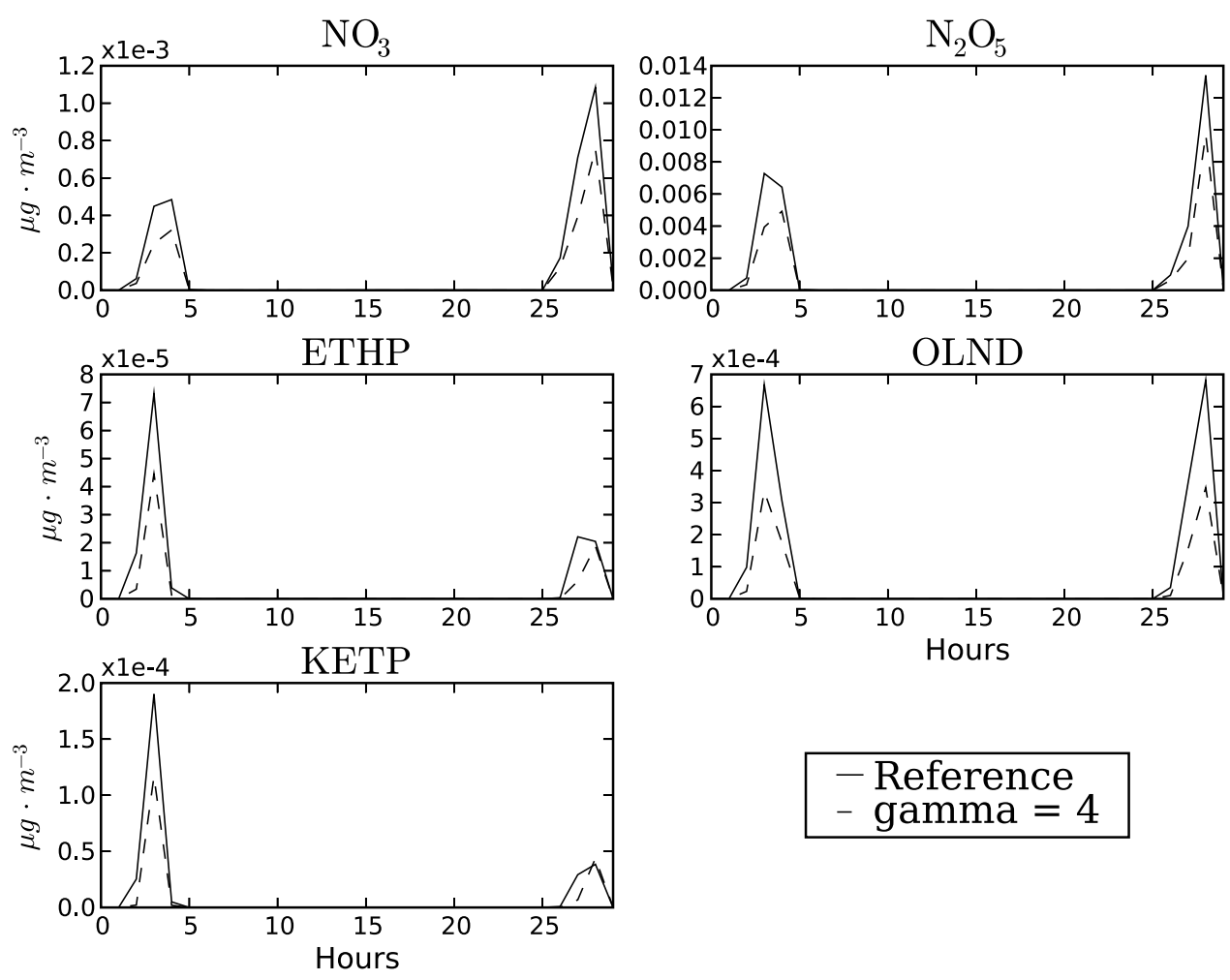

Figure 9. Time evolution of mean clipped concentrations for five species from Tables 3 and 4. The reference simulation $(\gamma=1+\sqrt{2} / 2)$ is compared to the simulation with $\gamma$ set to 4 . The remaining hours have the same behavior. This indicates that $\gamma=4$ is favorable at sunrise.

\subsubsection{Influence of $\gamma$}

[85] Highly clipped concentrations appear at sunrise, when photolysis rates increase $(\beta>1$, section 4.1$)$. In this case, $\gamma>1+\sqrt{2} / 2$. Indeed, higher values of $\gamma$ decrease clipped concentrations, as shown in Figure 9. Meanwhile the impact on the concentrations is low (see Figure 10). Higher values are however not advocated since it may lead to instabilities. For instance, with $\gamma=5$, the simulation is unstable. In addition, since the changes are negligible for the main species $\left(\mathrm{O}_{3}, \mathrm{SO}_{2}\right.$, even $\left.\mathrm{NO}_{2}\right)$, the new value of $\gamma$ does not bring much improvements to the simulation results.

[86] With $\gamma=\gamma^{+}(\beta)$, the results are not improved (Figure 11). The approximation of $\beta$ (maximum ratio of the values on the diagonals of Jacobian matrices) is probably too coarse.

\subsubsection{Conclusion}

[87] Concentrations are mainly clipped at sunrise, when the system is nonautonomous because of increasing photolysis rates. Nevertheless clipped concentrations remain low, except in a few cases. As for the value of $\gamma$, the classical choice seems to be a good compromise which ensures stability.

\section{Advection and Diffusion}

\subsection{Background}

[88] There are many issues related to advection, including (1) mass conservation and (2) numerical diffusion, which is a crucial point, especially for accidental releases in a clean atmosphere (strong gradients near the sources).

[89] For the sake of clarity, we only present the algorithms for the monodimensional case:

$$
\frac{\partial c}{\partial t}+\frac{\partial(u c)}{\partial x}=0
$$

where $u$ is the wind velocity. Let $\Delta t$ be the time step and $\Delta x$ the grid size. We define $t_{n}=n \Delta t$ and $x_{i-1 / 2}=(i-1 / 2) \Delta x$. Let $c_{i}^{n}$ be the numerical value of $\mathrm{c}$ at $t_{n}$ in the cell $\left[x_{i}-1 / 2\right.$, $\left.x_{i}+1 / 2\right]$. The conservative form of the numerical scheme is

$$
c_{i}^{n+1}=c_{i}^{n}+F_{i-1 / 2}^{n}-F_{i+1 / 2}^{n},
$$

with $F_{i}^{n}-1 / 2$ the numerical flux at $x_{i}-1 / 2$.

[90] The key focus of this section is to investigate if highorder schemes and flux limiters are required. Three algorithms are then compared: (1) the upwind scheme (positive but diffusive),

$$
F_{i+1 / 2}= \begin{cases}\nu_{i+1 / 2} c_{i} & \text { if } u_{i+1 / 2} \geq 0 \\ -\nu_{i+1 / 2} c_{i+1} & \text { if } u_{i+1 / 2}<0\end{cases}
$$

(2) a third-order scheme without flux limiter (little diffusive, but not positive [Spee, 1998]),

$$
F_{i+1 / 2}= \begin{cases}\nu_{i+1 / 2}\left(c_{i}+d_{0}\left(\nu_{i+1 / 2}\right)\left(c_{i+1}-c_{i}\right)+d_{1}\left(\nu_{i+1 / 2}\right)\left(c_{i}-c_{i-1}\right)\right) & \text { if } u_{i+1 / 2} \geq 0 \\ -\nu_{i+1 / 2}\left(c_{i+1}+d_{0}\left(\nu_{i+1 / 2}\right)\left(c_{i}-c_{i+1}\right)+d_{1}\left(\nu_{i+1 / 2}\right)\left(c_{i+1}-c_{i+2}\right)\right) & \text { if } u_{i+1 / 2}<0\end{cases}
$$



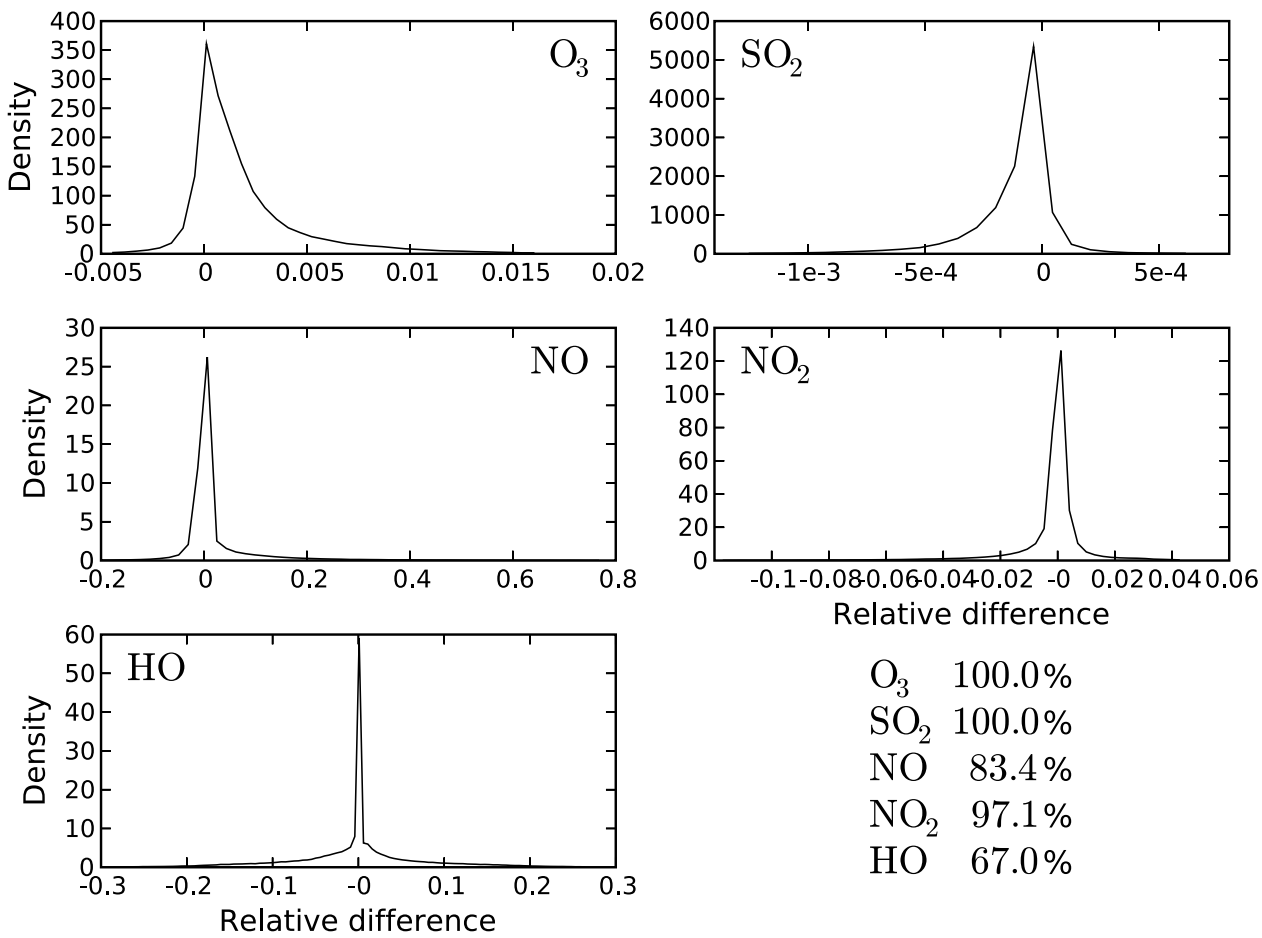

Relative difference

$\mathrm{O}_{3} \quad 100.0 \%$

$\mathrm{SO}_{2} 100.0 \%$

NO $83.4 \%$

$\mathrm{NO}_{2} \quad 97.1 \%$

HO $\quad 67.0 \%$

Figure 10. Reference simulation $(\gamma=1+\sqrt{2} / 2)$ versus simulation with $\gamma$ set to 4 : relative frequency distribution of the distance $\Delta$ and agreement coefficients for the five species. The impact is low.
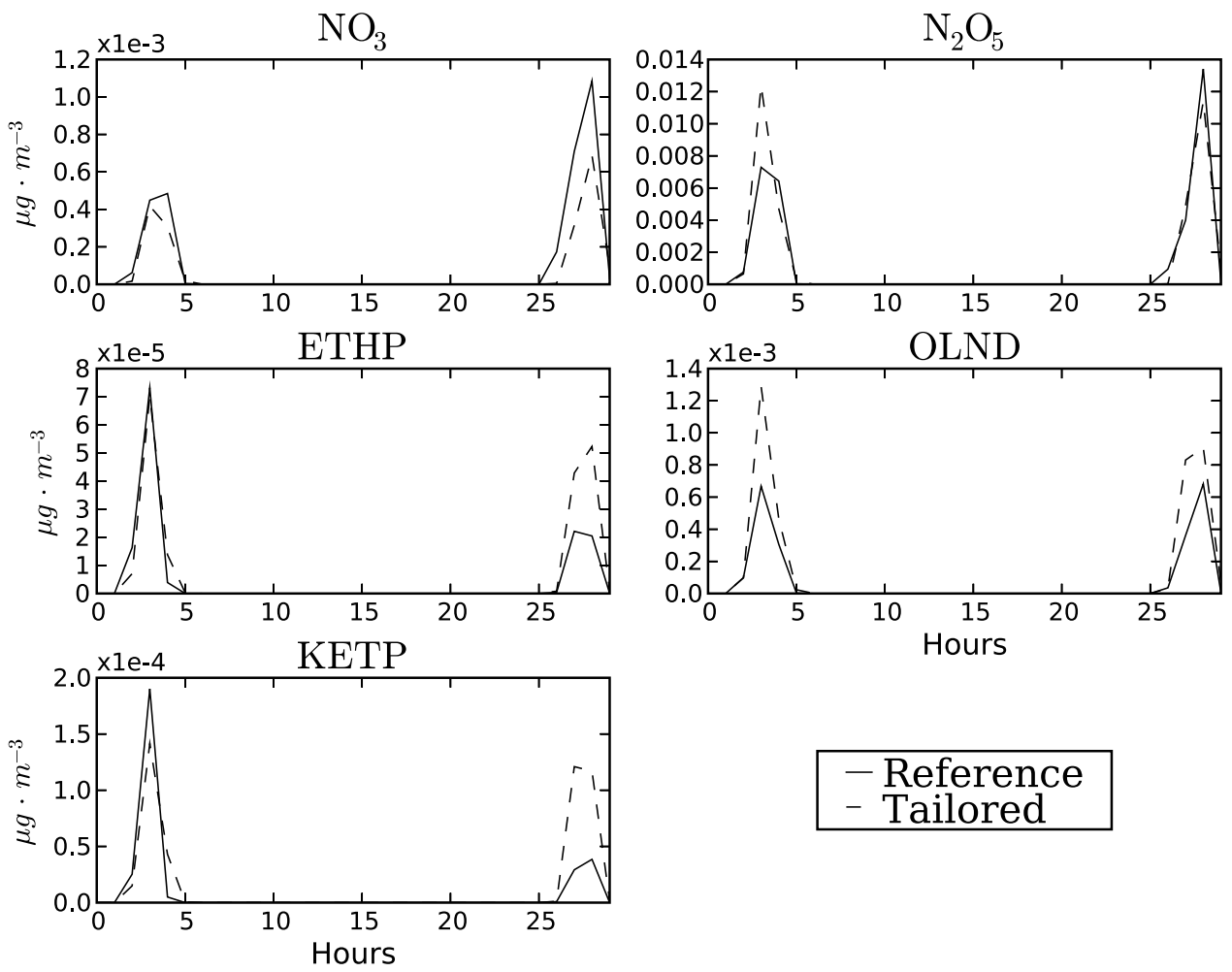

Figure 11. Time evolution of mean clipped concentrations for five species from Tables 3 and 4 . The reference simulation $(\gamma=1+\sqrt{2} / 2)$ is compared to the simulation with $\gamma \simeq \gamma^{+}(\beta)$. Only the first 30 hours are shown; the remaining hours have the same behavior. 

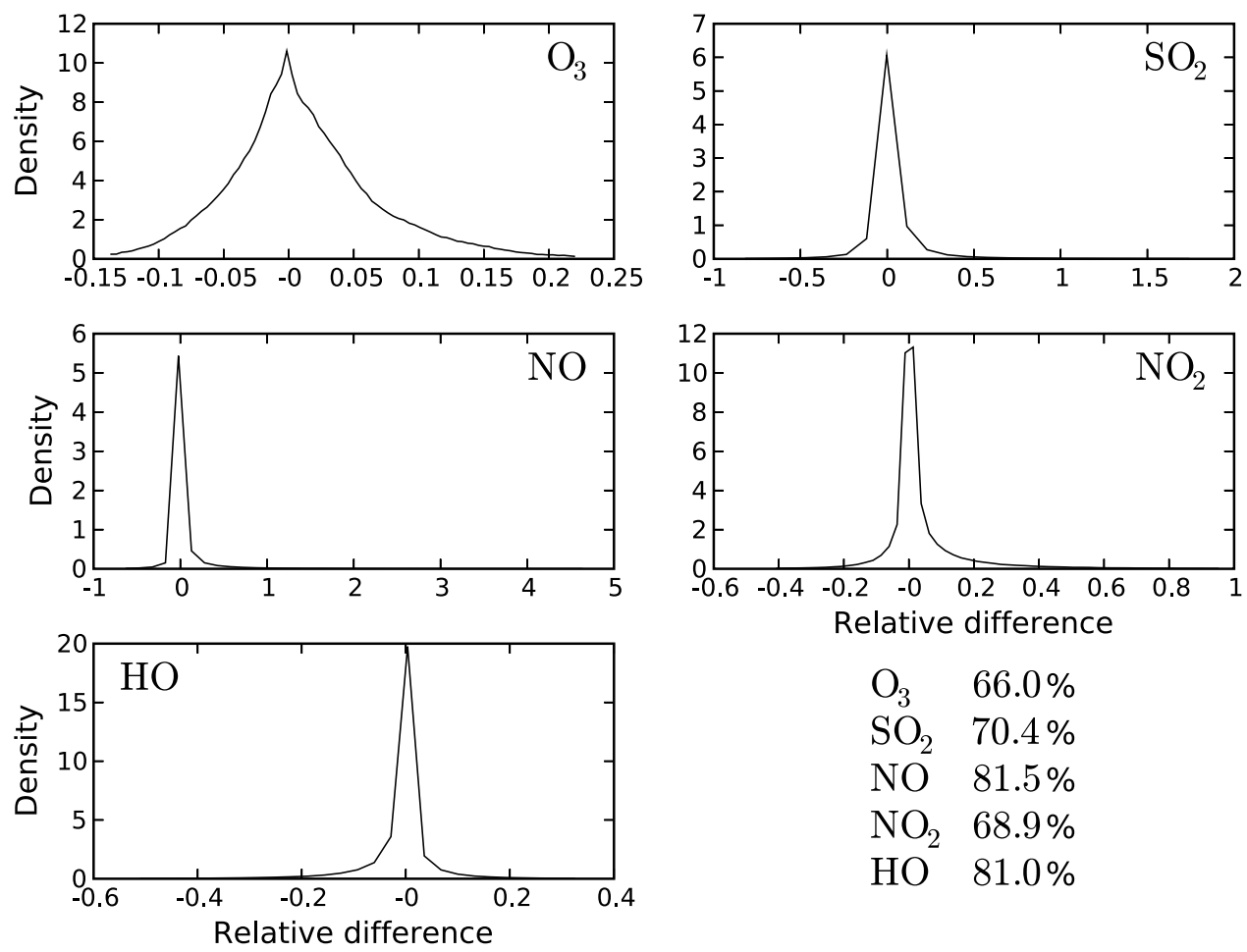

$\mathrm{O}_{3} \quad 66.0 \%$

$\mathrm{SO}_{2} \quad 70.4 \%$

NO $81.5 \%$

$\mathrm{NO}_{2} \quad 68.9 \%$

HO $\quad 81.0 \%$

Figure 12. Third-order scheme with flux limiter versus upwind scheme: relative frequency distribution of the distance $\Delta$ and agreement coefficients for the five species.
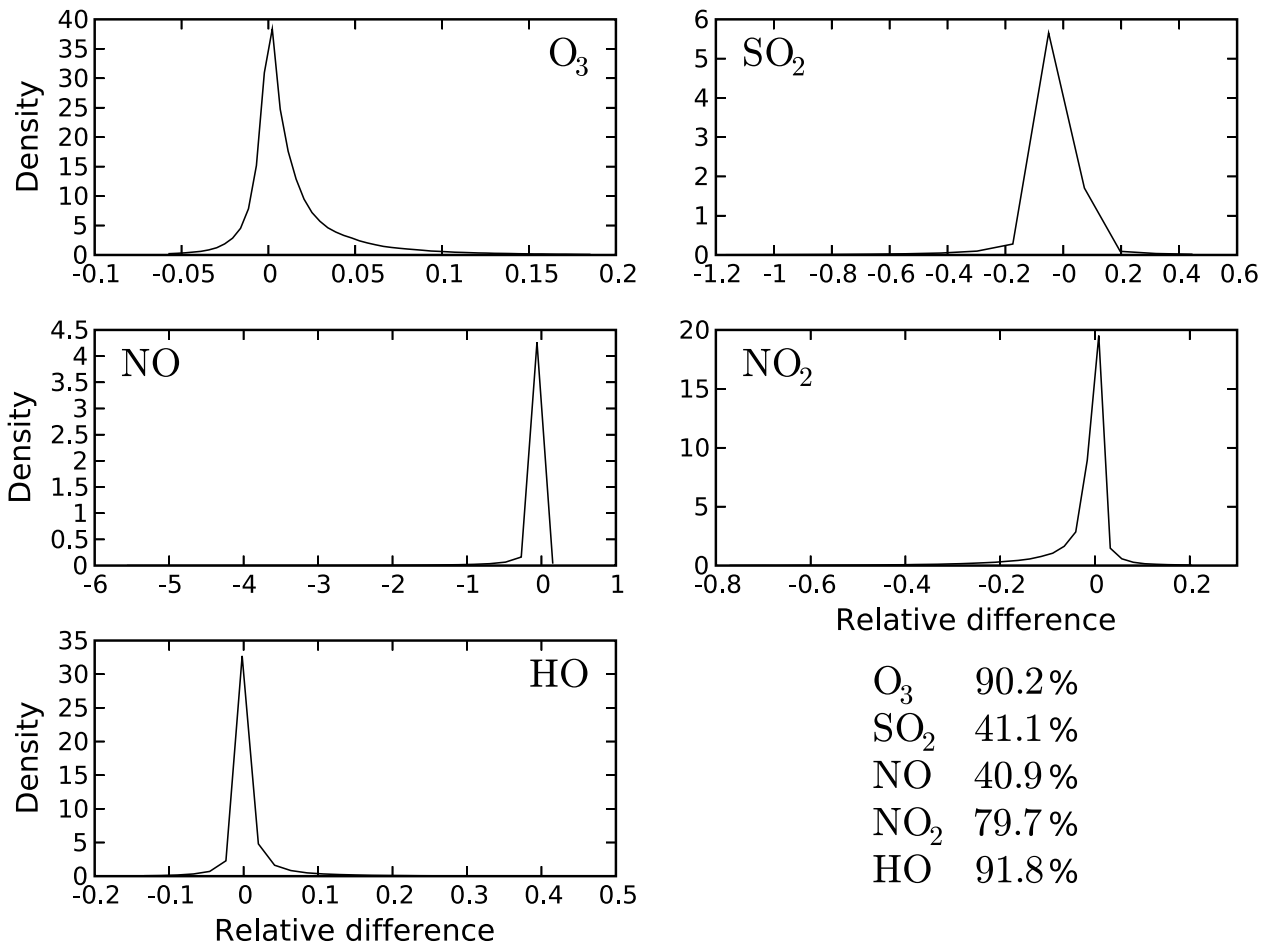

$\mathrm{O}_{3} \quad 90.2 \%$

$\mathrm{SO}_{2} \quad 41.1 \%$

$\mathrm{NO} \quad 40.9 \%$

$\mathrm{NO}_{2} \quad 79.7 \%$

HO $\quad 91.8 \%$

Figure 13. Third-order scheme with flux limiter versus third-order scheme without flux limiter: relative frequency distribution of the distance $\Delta$ and agreement coefficients for the five species. 

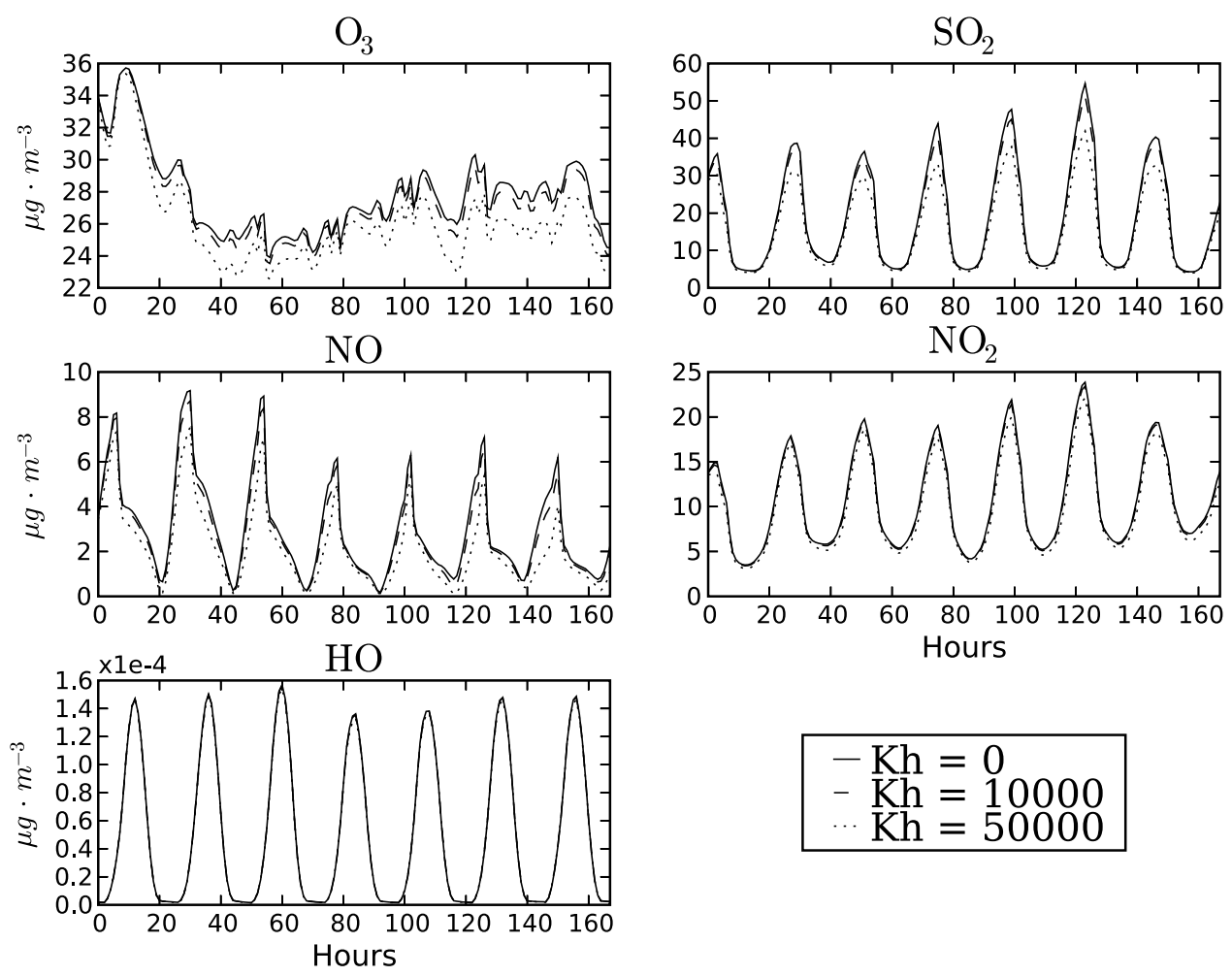

Figure 14. Time evolution of spatial standard deviations, with $K_{h}=0, K_{h}=10,000 \mathrm{~m}^{2} \mathrm{~s}^{-1}$ and $K_{h}=$ $50,000 \mathrm{~m}^{2} \mathrm{~s}^{-1}$.

and (3) the same third-order scheme, with a Sweby-type flux limiter (intermediate [Verwer et al., 2002]), which is the reference scheme of Polair3D,

$F_{i+1 / 2}=\left\{\begin{array}{ll}\nu_{i+1 / 2}\left(c_{i}+\psi\left(\nu_{i+1 / 2}, \theta_{i}\right)\left(c_{i+1}-c_{i}\right)\right) & \text { if } u_{i+1 / 2} \geq 0 \\ -\nu_{i+1 / 2}\left(c_{i+1}+\psi\left(\nu_{i+1 / 2}, \frac{1}{\theta_{i+1}}\right)\left(c_{i}-c_{i+1}\right)\right) & \text { if } u_{i+1 / 2}<0\end{array} ;\right.$

where $u_{i+1 / 2} \simeq u\left(x_{i+1 / 2}, t_{n}\right)$ and $\nu_{i+1 / 2}=\left|u_{i+1 / 2}\right| \frac{\Delta t}{\Delta x}$ is the CFL number. The limiter function is

$$
\psi(\nu, \theta)=\max \left(0, \min \left(1, d_{0}(\nu)+d_{1}(\nu) \theta, \frac{1-\nu}{\nu} \theta\right)\right)
$$

with

$$
d_{0}(\nu)=\frac{1}{6}(2-\nu)(1-\nu), d_{1}(\nu)=\frac{1}{6}\left(1-\nu^{2}\right), \theta_{i}=\frac{c_{i}-c_{i-1}}{c_{i+1}-c_{i}}
$$

For this scheme, the CFL condition is $\nu_{i+1 / 2} \leq 1$.

\subsection{Numerical Test}

[91] A strong impact of the advection scheme is found. The first-order upwind scheme is so diffusive that its agreement coefficient with the reference simulation (thirdorder scheme with flux limiter) falls to $66 \%$ for ozone. Figure 12 illustrates the results.

\begin{tabular}{|c|c|c|c|c|c|}
\hline Comparison & $\mathrm{O}_{3}$ & $\mathrm{SO}_{2}$ & NO & $\mathrm{NO}_{2}$ & $\mathrm{HO}$ \\
\hline$\Delta t=600 \mathrm{~s} / \Delta t=1800 \mathrm{~s}$ & 58.5 & 90.9 & 51.4 & 69.7 & 55.0 \\
\hline Reference/first order for advection & 66.0 & 70.4 & 81.5 & 68.9 & 81.0 \\
\hline$K_{h}=10000 \mathrm{~m}^{2} \mathrm{~s}^{-1} / K_{h}=50000 \mathrm{~m}^{2} \mathrm{~s}^{-1}$ & 80.0 & 81.9 & 18.4 & 65.7 & 83.9 \\
\hline Reference/third order for advection & 90.2 & 41.1 & 40.9 & 79.7 & 91.8 \\
\hline Boundary conditions in diffusion/boundary conditions in chemistry & 97.0 & 88.2 & 80.4 & 84.9 & 80.7 \\
\hline$K_{h}=10000 \mathrm{~m}^{2} \mathrm{~s}^{-1} / K_{h}=0 \mathrm{~m}^{2} \mathrm{~s}^{-1}$ & 97.9 & 84.2 & 90.7 & 85.4 & 94.5 \\
\hline$\Delta t=600 \mathrm{~s} / \Delta t=30 \mathrm{~s}$ & 97.9 & 96.8 & 85.1 & 91.2 & 74.0 \\
\hline Reference/second-order splitting & 98.5 & 96.3 & 78.8 & 89.0 & 81.7 \\
\hline $\mathrm{ADC} / \mathrm{ACD}$ & 99.6 & 98.9 & 10.4 & 61.4 & 68.3 \\
\hline Reference $/ \gamma^{+}$ & 99.7 & 100.0 & 94.6 & 97.7 & 97.9 \\
\hline $\mathrm{ADC} / \mathrm{DCA}$ & 99.9 & 93.1 & 86.4 & 88.0 & 74.8 \\
\hline Reference/internal splitting & 99.9 & 98.8 & 89.5 & 91.0 & 73.5 \\
\hline Reference $/ \gamma=4$ & 100.0 & 100.0 & 83.4 & 97.1 & 67.0 \\
\hline Reference/source splitting & 100.0 & 100.0 & 93.9 & 90.7 & 77.8 \\
\hline
\end{tabular}

Table 5. Summary of Agreement Coefficients for the Main Tests of the Continental Case ${ }^{a}$

${ }^{a}$ The comparisons are ranked according to their ozone agreement coefficients. 
Table 6. Summary of Agreement Coefficients for the Main Tests of the Regional Case ${ }^{\mathrm{a}}$

\begin{tabular}{lccccc}
\hline \multicolumn{1}{c}{ Comparison } & $\mathrm{O}_{3}$ & $\mathrm{SO}_{2}$ & $\mathrm{NO}$ & $\mathrm{NO}_{2}$ & $\mathrm{HO}$ \\
\hline$\Delta t=600 \mathrm{~s} / \Delta t=1800 \mathrm{~s}$ & 40.9 & 60.4 & 76.9 & 34.8 & 16.5 \\
ADC/ACD & 64.5 & 90.0 & 11.7 & 33.2 & 22.5 \\
First-order splitting/second-order splitting & 83.4 & 66.5 & 19.4 & 71.2 & 17.9 \\
Boundary conditions in diffusion/boundary conditions in chemistry & 79.0 & 71.6 & 64.9 & 87.3 & 37.4 \\
$\Delta t=600 \mathrm{~s} / \Delta t=30 \mathrm{~s}$ & 83.2 & 50.2 & 78.5 & 75.2 & 35.8 \\
Reference/first order for advection & 97.6 & 80.5 & 80.0 & 92.6 & 93.1 \\
Reference/third order for advection & 99.7 & 91.6 & 91.4 & 99.1 & 99.2 \\
$K_{h}=5 \mathrm{~m}^{2} \mathrm{~s}^{-1} / K_{h}=50 \mathrm{~m}^{2} \mathrm{~s}^{-1}$ & 100.0 & 97.5 & 96.3 & 100.0 & 100.0 \\
Reference $/ \gamma=4$ & 100.0 & 100.0 & 81.3 & 100.0 & 12.5 \\
$K_{h}=5 \mathrm{~m}^{2} \mathrm{~s}^{-1} / K_{h}=0 \mathrm{~m}^{2} \mathrm{~s}^{-1}$ & 100.0 & 100.0 & 99.9 & 100.0 & 100.0 \\
Reference $/ \gamma^{+}$ & 100.0 & 100.0 & 100.0 & 100.0 & 100.0 \\
\hline
\end{tabular}

${ }^{\mathrm{a}}$ The comparisons are ranked according to their ozone agreement coefficients.

[92] There are less differences between the reference scheme and the third-order scheme (without flux limiter), but the impact is still high. Figure 13 shows the results.

[93] It is therefore advocated to use the third-order scheme with flux limiting.

\subsection{Impact of Horizontal Diffusion}

[94] The horizontal diffusion coefficient is not a well known physical parameter. It is sometimes set to zero because the advection scheme introduces numerical diffusion. In order to assess the impact of the coefficient, three simulations are performed with the following horizontal diffusion coefficients: $K_{h}=0 \mathrm{~m}^{2} \mathrm{~s}^{-1}, K_{h}=10,000 \mathrm{~m}^{2} \mathrm{~s}^{-1}$ and $K_{h}=50,000 \mathrm{~m}^{2} \mathrm{~s}^{-1}$.

[95] Spatial means of output concentrations are not affected by the coefficient. As expected, maxima and (spatial) standard deviations are clearly modified when $K_{h}=50,000 \mathrm{~m}^{2} \mathrm{~s}^{-1}$ and somewhat modified for $K_{h}=10,000 \mathrm{~m}^{2} \mathrm{~s}^{-1}$. Figure 14 shows the impacts on the standard deviation.

\section{Conclusion}

[96] In this article we have investigated some numerical issues for chemistry-transport models with the use of the Polyphemus platform and model-to-model comparisons. Table 5 gathers the main results. One can conclude that the time step should not be increased above $600 \mathrm{~s}$, that the choice of the advection scheme is a key point, that the horizontal diffusion coefficient may have a strong impact for high horizontal diffusions. Issues related to operator splitting are less prominent.

[97] The results obtained at continental scale cannot be directly transposed to the regional case (see Table 6). For instance, the time step has better to be small enough to avoid splitting errors.

[98] Further conclusions should take into account the purpose of the simulations. The model species are not sensitive to the same numerical choices. For a given species, the impact may be high on the maxima but not on averaged concentrations. Previous conclusions are mainly drawn for hourly ozone concentrations.

[99] Numerical schemes are source of errors and therefore of uncertainties. Nevertheless, this uncertainty should be compared to the uncertainty due to coarse input data or due to physical parameterizations. For instance, Mallet and Sportisse [2006a] show that the relative uncertainty on ozone concentrations is higher than $16 \%$ (relative standard deviation), which is clearly above the impact of numerical schemes.

[100] Future work will be devoted to the extension to multiphase models (aerosols). Moreover configurations with high resolutions should be studied as well since the CTMs resolutions should increase in the following years.

\section{References}

Ahmad, I., and M. Berzins (1997), An algorithm for ODEs from atmospheric dispersion problems, Appl. Numer. Math., 25, 137-149.

Ascher, U., S. Ruuth, and B. Wetton (1995), Implicit-explicit methods for time-dependent partial differential equations, SIAM J. Numer. Anal., 32, $797-823$.

Berzins, M., and J. M. Ware (1996), Solving convection and convectionreaction problems using the method of lines, Appl. Numer. Math., 20, $83-99$.

Boutahar, J., S. Lacour, V. Mallet, D. Quélo, Y. Roustan, and B. Sportisse (2004), Development and validation of a fully modular platform for numerical modelling of air pollution: POLAIR, Int. J. Environ Pollut., 22, 17-28.

Carmichael, G. R., A. Sandu, F. Potra, V. Damian, and M. Damian (1996), The current state and the future directions in air quality modeling, Syst. Anal. Modell. Simul., 25, 75-105.

Djouad, R., B. Sportisse, and N. Audiffren (2002), Numerical simulation of aqueous-phase atmospheric models: Use of a non-autonomous Rosenbrock method, Atmos. Environ., 36, 873-879.

Frank, J., W. Hundsdorfer, and J. G. Verwer (1997), On the stability of implicit-explicit linear multistep methods, Appl. Numer. Math., 25, 193 205.

Frolkovič, P. (2002), Flux-based method of characteristics for contaminant transport in flowing groundwater, Comput. Visualization Sci., 5, 73-83.

Gery, M. W., G. Z. Whitten, J. P. Killus, and M. C. Dodge (1989), A photochemical kinetics mechanism for urban and regional scale computer modeling, J. Geophys. Res., 94, 12,925-12,956.

Horowitz, L. W., et al. (2003), A global simulation of tropospheric ozone and related tracers: Description and evaluation of MOZART, version 2 , J. Geophys. Res., 108(D24), 4784, doi:10.1029/2002JD002853.

Hundsdorfer, W., and E. Spee (1995), An efficient horizontal advection scheme for the modeling of global transport of constituents, Mon. Weather Rev., 123, 3554-3564.

Jacobson, M. Z. (2005), Fundamentals of Atmospheric Modeling, 2nd ed. Cambridge Univ. Press, New York.

Knoth, O., and R. Wolke (1994), A comparison of fast chemical kinetic solvers in a simple vertical diffusion model, Air Pollution Modelling and Its Applications X, pp. 147-155, Springer, New York.

Knoth, O., and R. Wolke (1998), An explicit-implicit numerical approach for atmospheric chemistry-transport modeling, Atmos. Environ., 32, $1785-1797$

Knoth, O., and R. Wolke (1999), Strang splitting versus implicit-explicit methods in solving chemistry transport models, in Proceedings EUROTRAC Symposium '98, edited by P. M. Borrell and P. Borrell, vol. 2, pp. 524-528, WIT Press, Billerica, Mass.

Lanser, D., and J. G. Verwer (1999), Analysis of operator splitting for advection-diffusion-reaction problems from air pollution modelling, J. Comput. Appl. Math., 111, 201-216. 
Lin, S.-J., and R. B. Rood (1996), Multidimensional flux-form semiLagrangian transport schemes, Mon. Weather Rev., 124, 2046-2070.

Mallet, V., and B. Sportisse (2004), 3-D chemistry-transport model Polair: Numerical issues, validation and automatic-differentiation strategy, Atmos. Chem. Phys. Disc., 4, 1371-1392.

Mallet, V., and B. Sportisse (2005a), A comprehensive study of ozone sensitivity with respect to emissions over Europe with a chemistry-transport model, J. Geophys. Res., 110, D22302, doi:10.1029/2005JD006234.

Mallet, V., and B. Sportisse (2005b), Data processing and parameterizations in atmospheric chemistry and physics: The AtmoData library, Tech. Rep. 2005-12, Cent. d'Enseignement et de Rech. en Environ. Atmos., Marne la Vallée, France.

Mallet, V., and B. Sportisse (2006a), Uncertainty in a chemistry-transport model due to physical parameterizations and numerical approximations: An ensemble approach applied to ozone modeling, J. Geophys. Res., 111, D01302, doi:10.1029/2005JD006149.

Mallet, V., and B. Sportisse (2006b), Ensemble-based air quality forecasts: A multimodel approach applied to ozone, J. Geophys. Res., 111, D18302, doi:10.1029/2005JD006675

Mallet, V., et al. (2007), Technical note: The air quality modeling system Polyphemus, Atmos. Chem. Phys. Disc., 7(3), 6459-6486.

McRae, G. J., W. R. Goodin, and J. H. Seinfeld (1982), Numerical solution of the atmospheric diffusion equation for chemically reactive flows, J. Comput. Phys., 45, 1-42.

Perot, J. B. (1993), An analysis of the fractional step method, J. Comput. Phys., 108, 51-58.

Pourchet, A., V. Mallet, D. Quélo, and B. Sportisse (2005), Some numerical issues in chemistry-Transport models-A comprehensive study with the Polyphemus/Polair3D platform, Tech. Rep. 2005-26, Cent. d'Enseignement et de Rech. en Environ. Atmos., Marne la Vallée, France.

Preussner, P. R., and K. P. Brand (1981), Application of a semi-implicit Euler method to mass action kinetics, Chem. Eng. Sci., 36, 1633-1641.

Quélo, D., V. Mallet, and B. Sportisse (2005), Inverse modeling of $\mathrm{NO}_{\mathrm{x}}$ emissions at regional scale over northern France: Preliminary investigation of the second-order sensitivity, J. Geophys. Res., 110, D24310, doi:10.1029/2005JD006151.

Restelli, M., L. Bonaventura, and R. Sacco (2006), A semi-Lagrangian discontinuous Galerkin method for scalar advection by incompressible flows, J. Comput. Phys., 216, 195-215.

Russell, A., and R. Dennis (2000), NARSTO critical review of photochemical models and modeling, Atmos. Environ., 34, 2234-2283.

Sandu, A. (2001), Positive numerical integration methods for chemical kinetic systems, J. Comput. Phys., 170, 589-602.

Sandu, A., F. A. Potra, G. R. Carmichael, and V. Damian (1996), Efficient implementation of fully implicit methods for atmospheric chemical kinetics, J. Comput. Phys., 129, 101-110.

Sandu, A., J. G. Verwer, J. G. Blom, E. J. Spee, G. R. Carmichael, and F. A. Potra (1997a), Benchmarking stiff ODE solvers for atmospheric chemistry problems II: Rosenbrock solvers, Atmos. Environ., 31, $3459-3472$

Sandu, A., J. G. Verwer, M. V. Loon, G. R. Carmichael, F. A. Potra, D. Dabdub, and J. H. Seinfeld (1997b), Benchmarking stiff ODE solvers for atmospheric chemistry problems-I. Implicit vs explicit, Atmos. Environ., 31, 3151-3166.

Seinfeld, J. H., and S. N. Pandis (1998), Atmospheric Chemistry and Physics: From Air Pollution to Climate Change, Wiley-Interscience, Hoboken, N. J. Spee, E. J. (1998), Numerical methods in global transport-chemistry models, Ph.D. thesis, Univ. of Amsterdam, Amsterdam.

Sportisse, B. (2000), An analysis of operator splitting techniques in the stiff case, J. Comput. Phys., 161, 140-168.

Sportisse, B. (2007), A review of current issues in air pollution modeling and simulation, J. Comput. Geosci., 11(2), 159-181.

Stockwell, W. R., F. Kirchner, M. Kuhn, and S. Seefeld (1997), A new mechanism for regional atmospheric chemistry modeling, J. Geophys. Res., 102, 25,847-25,879.

Strang, G. (1968), On the construction and comparison of difference schemes, SIAM J. Numer. Anal., 5, 506-517.

Sun, P. (1996), A pseudo-non-time-splitting method in air quality modeling, J. Comput. Phys., 127, 152-157.

Verwer, J. G. (1994), Gauss-Seidel iteration for stiff ODES from chemical kinetics, SIAM J. Sci. Comput., 15, 1243-1250.

Verwer, J. G., and D. Simpson (1995), Explicit methods for stiff ODEs from atmospheric chemistry, Appl. Numer. Math., 18, 413-430.

Verwer, J. G., J. G. Blom, and W. Hundsdorfer (1996a), An implicit-explicit approach for atmospheric transport-chemistry problems, Appl. Numer. Math., 20, 191-209.

Verwer, J. G., J. G. Blom, M. van Loon, and E. J. Spee (1996b), A comparison of stiff ODE solvers for atmospheric chemistry problems, Atmos. Environ., 30, 49-58.

Verwer, J. G., E. J. Spee, J. G. Blom, and W. Hundsdorfer (1999), A second-order Rosenbrock method applied to photochemical dispersion problems, SIAM J. Sci. Comput., 20, 1456-1480.

Verwer, J. G., W. Hundsdorfer, and J. G. Blom (2002), Numerical time integration for air pollution models, Surv. Math. Indust., 10, 107-174.

Wolke, R., and O. Knoth (2000), Implicit-explicit Runge-Kutta methods applied to atmospheric chemistry-transport modelling, Environ. Modell. Softw. $15,711-719$

Zlatev, Z. (1995), Computer Treatment of Large Air Pollution Models, Springer, New York.

V. Mallet, A. Pourchet, D. Quélo, and B. Sportisse, CEREA, École Nationale des Ponts et Chaussées, 6-8 Avenue Blaise Pascal, Champssur-Marne, F-77455 Marne-La-Vallée, France. (vivien.mallet@cerea.enpc.fr) 